\title{
Utber neuere Eiweißreaktionen der Spinalflüssigkeit, ihre praktische und theoretische Bedeutung mit besonderer Berücksichtigung ihrer Beziehungen zum Antikörpergehalt des Liquor cerebrospinalis.
}

\author{
Von \\ V. Kafka und H. Rautenberg. \\ (Aus der Staatsirrenanstalt Friedrichsberg-Hamburg [Direktor: Professor \\ Dr. Weygandt].) \\ Mit 1 Textfigur.
}

(Eingegangen am 29. November 1913.)

\section{Einleitung und Fragestellungen.}

Trotz vielfacher Untersuchungen der jüngeren und jüngsten Zeit ist es noch nicht gelungen, über die chemische Natur der in der Spinalflüssigkeit befindlichen Eiweißkörper völlige Klarheit zu gewinnen. Die Gründe dafür sind in erster Linie darin zu suchen, daß nicht die genügenden Mengen zur genauen chemischen Untersuchung zur Verfügung stehen, daß die Eiweilßkörper im Liquor nur in sehr geringer Menge vorhanden sind und in einer gegenüber dem Blute verschiedenen Verteilung. Aus ähnlichen Gründen besitzen wir auch noch keine $\mathrm{Me}$ thode, die in vollständiger, befriedigender Weise uns gestattet, den Gesamteiweißgehalt der Spinalflüssigkeit zu bestimmen. Gerade die neueren Methoden, wie die von Zaloziecki ${ }^{17}$ ), Mestrezat ${ }^{11}$ ) u. a. sind für die Laboratoriumsverwendung etwas umständlich und entbehren nicht eines ins Gewicht fallenden subjektiven Faktors. Wir wollen im Verlaufe dieser Lntersuchungen zeigen, daß gerade die alte Nißlsche Methorle, wenn sie mit den nötigen Kautelen angewendet wird, sich nicht nur leicht anstellen läßt, sondern auch objektive Resultate ergibt und die Fehlerquellen dann sehr geringe sind. Aber auch die praktische Verwendbarkeit der Liquorreaktionen ist noch nicht genügend nachgeprüft, um uns vollkommen klare Indikationen zu geben. Wenn auch der Wert der Nonne - A pelt - Sch u m m schen Phase I Reaktion zur Differentialdiagnose sehr groß ist, wie die vielen Arbeiten der letzten Zeit gezeigt haben, so glauben wir doch, daß wir zur Kontrolle von Heilungsversuchen noch feinerer Methode bedürfen, zumal es sich ja hier dlarum handelt, nachweisen zu können, daß z. B. in einem gut behandelten Fall der Liquor cerebrospinalis in bezug auf 
Gesamteiweiß- und Globulingehalt wirklich normal ist. Gennerich ${ }^{3}$, der ja aus geringen Liquorveränderungen so wichtige Schlüsse zieht, hat in seinen ausgezeichneten Untersuchungen solche Rcaktionen nicht herangezogen. Außerdem scheint es aber Eiweißreaktionen zu geben, die, wie z. B. die von Braun-Husler uns andere diagnostische Aufschlüsse erteilen als die übrigen Globulinreaktionen. Sind wir also bezüglich der theoretischen und praktischen Bedeutung der Liquorreaktionen noch nicht am Ende unserer Untersuchung angelangt, so sind wir bezüglich einer anderen sehr wichtigen Frage noch weiter zur ück. Es sind die Versuche zur Klärung der Beziehungen zwischen Eiweißart und -menge und Antikörpergehalt dor Spinalflüssigkeit und damit zusammenhängend das Problem der „Permeabilität der Meningen“. Es sei gestattet, gleich hier ausführlicher auf dieses von uns schon mehrmals erörterte, aber sehr aktuelle Gebiet cinzugehen. Pelanntlich ist für die akuten Meningitiden von verschiedenen Autoren eine erhöhte Permeabilität der Meningen gefunden worlen, ja sie wurde von Mestrezat sogar diagnostisch ausgenutzt. Wenn man von erhöhter Permeabilität spricht, so trifft dies für viele Stoffe nicht zu, da sio im normalen Liquor überhaupt nicht auffindbar sind, so daß die Meningitis übcrhaupt erst die Permeabilität erzeugt. Der Ausdruck Permeabilität der Meningen muß natürlich, um richtig zu sein, durch Permeabilität der Meningealgefäße und des Plexus ersetzt werden. Wicweit einerseits die Meningealgefäße, andrerseits der Plexus daran beteiligt sind, läßt sich noch nicht mit Sicherheit sagen, doch scheinen Untersuchungen

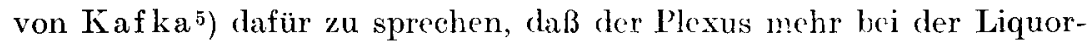
sekretion, die Meningealgefäße mehr be i diesen pathologischen Vorgängen in Funktion treten. Es wurde nun ron Weil und Kaf ka $\left.{ }^{15}\right)^{16}$ ) nachgewiesen, daß eine solche erhöhte Durchgängigkeit frcilich in geringem MaBe und in anderer Art sich auch in der gröberen Mehrzahl $(87 \%)$ der Paralysefälle nachweisen läßt, indem de'x im Blut fast immer vorhandene hämolytische Normalamboceptor in solchen Fällen in der Spinalflüssigkeit zu finden ist. Kafka lionnte auch durch Versuche mit per os-Einverleibung von Lranin ein erhöhtes Übergehen dieses Stoffes in die Spinalflüssigkeit für eine Anzahl von Paralysefällen feststellen. Während nun Weil und Kafka die erhöhte Permeabilität der Meningealgefäße als etwas für die Paralyse (harakteristisches ansahen, was durch eine große Anzahl von Nachprifern bestätigt wurde, glaubte Zalozicc $\mathrm{ki}^{18}$ ) sich durch seine Untersuchungen zu dem Schlusse berechtigt, daß bei jeder stärkeren Eiweißvermehrung der Spinalflüssigkeit auch Normalamboceptoren in derselben nachweisbar sein müßten (wenn der Serumtiter ein genügend hoher ist) und erklärte, daB die ,Untersuchungen auf hämolytischen Amboceptor... durch die einfacheren und zuverlässigeren Eiweißrcalitionen ersctzbar..." seien. Es 
wird also durch diese Worte ausgedrückt, daß ein enger Parallelismus zwischen Eiweißreaktionen einerseits, Antikörpergehalt andererseits bestehen muß. Eine Kritik dieser Behauptungen sei an den Schluß dieser Arbeit gestellt, bis über die am eigenen Material und in früheren Publikationen gemachten Beobachtungen berichtet worden ist. Um diese Frage zu prüfen, muß man vergleichend Antikörperuntersuchungen wie auch Gesamteiweiß- und Globulimbestimmungen der Spinalflüssigkeit vornehmen, und zwar nicht nur an einem Material mit sehr starker Eiweißvermehrung, wie es Za loziccki getan hat, sondern auch an einem solchen mit schwächeren und negativen Eiweiß- und Zellbefunden. Erst dann wird sich herausstellen, ob ein derartiger Zusammenhang, wie er oben berichtet worden ist, wirklich besteht, wieweit meningitische Erscheinungen ursächlich in Betracht kommen, und ob und wieweit dem Normalamboceptorübertritt eine Sonderstellung gebührt und dieses Phänomen für die Frage der erhöhten Permeabilität zu verwerten ist. Es sei nochmals darauf aufmerksam gemacht, daß wir schon auf die Resultate früherer Untersuchungen fußend auf diese Frage Antwort geben könnten, wir wollen aber erst nach jeder Richtung hin untersuchtes Material vorführen, um uns keiner Lücke in der Beweisführung schuldig zu machen. Hier schließt sich ein zweites Problem an. Bekanntlich sollen Fermente, Antifermente, Präcipitine nur in einer der durch verschiedenes Aussalzen gefundenen Globulinfraktion enthalten sein, der Euglobulinfraktion [Marcus ${ }^{9}$, Fuld und Spiro' ${ }^{2}$ ), Spiro $\left.{ }^{14}\right)$ ]. Es ist daher von großem Interesse, verschiedene Fraktionen mit Ammoniumsulfat herzustellen und zu untersuchen, ob sich bei besonders starkem Auftreten einer bestimmten Fraktion auch besonders starker Antikörpergehalt im Liquor nachweisen läßt. Bei einer solchen Versuchsanordnung müssen wir auch jener Globuline gedenken, die durch niedrige Aussalzung mit Ammoniumsulfat gefällt werden, besonders des Fibrinogens. Re ye ${ }^{13}$ ) hat solche Versuche mit Erfolg für andere Körperflüssigkeiten angewendet und betont, daß der Nachweis des Fibrinogens durch Fibringerinnsel auf Schwierigkeiten stößt und die Bildung des Fibrins aus Fibrinogen unvollständig ist, so daß bei der U'mwandlung nach Hammarsten Verluste von 5-40\% der Fibrinogenmenge vorkommen. Dies spielt für den Liquor, wo die Fibrinogenmengen, wenn überhaupt vorhanden, sehr geringe sind, eine noch größere Rolle. Da ferner das Erscheinen von Fibrinogen in den Körperflüssigkeiten von diagnostischer und prognostischer Bedeutung ist, wie die Untersuchungen von $\mathbf{F}$. Hof $\operatorname{man} \mathbf{n}^{4}$ ) ergeben, müBte von vornherein eine solche Reaktion auch für die Liquorpathologie von Bedeutung sein.

Es ergeben sich also für unsere Untersuchungen folgende Fragen:

1. Welches ist die praktische brauchbarste Methode zur Bestimmung des Cresamteiweißes? 
2. Welche Beziehungen bestehen zwischen G'lobulin- und anderen Eiweißreaktionen und Gesamteiweißgehalt ?

3. Welche diagnostischen Vorteile bieten uns die verschiedenen Eiweißreaktionen?

4. Welche theoretischen Schlüsse lassen die verschiedenen Eiweißreaktionen auf die Natur der in der Spinalflüssigkeit befindlichen Eiweißstoffe ziehen?

5. Welche Bedeutung hat die Bestimmung der Fibringlobuline?

6. Gibt es eine Kla usnersche Reaktion der Spinalflüssigkeit?

7. Welche Beziehungen bestehen zwischen

a) der Globulin- und anderen qualitativen Eiweißreaktionen verschiedener Stärke,

b) dem Gesamteiweißgehalt und

a) dem Normalamboceptorgehalt,

B) dem Komplementgehalt der Spinalflüssigkeit, und zwar bei entsprechendem und nicht entsprechendem Serumtiter?

8. Bestehen Zusammenhänge zwischen Zellmenge resp. Zellart, Wassermannscher Reaktion und Normalamboceptorgehalt der Spinalflüssigkeit?

9. Wie gestaltet sich die Ausbeute für die Frage der „Permeabilität der Meningen"?

10. Welche diagnostischen, prognostischen und ev. pathogenetischen Erkenntnisse ergeben sich aus den Beziehungen zwischen Eiweiß- und Antikörpergehalt der Spinalflüssigkeit?

\section{Technik.}

Unsern Untersuchungen mußte vor allem eine brauchbare Methode zur Bestimmung des Gesamteiweißes zugrunde gelegt werden. Bei den uns zur Verfügung stehenden Liquormengen war eine Bestimmung durch Wägung ausgeschlossen. Gegenüber der diaphanometrischen Methode Mestrezats und der Zalozicckis schien uns doch die alte $\mathrm{Ni} ß$ lsche Bestimmung für unsere Zwecke geeigneter, doch nur dann, wenn man gewisse Punkte a ufs genaueste beobachtete. Vor allem müssen die Röhrchen geeicht werden, und zwar natürlich jedes allein. Die Eichung kann vermittels Wägung oder anderer verläßlicher quantitativer Methoden geschehen. Man geht damn von eiweißreichen Harnen aus, in denen man rlurch Verdünnungen die bestimmten Teilstriche der Nißl-Röhrehen entsprechenden Eiweißmengen herstellt. Natürlich müssen bei einer solchen Eichung die gleichen Kautelen beobachtet werden wie bei der eigentlichen Bestimmung selbst. Es muß solange zentrifugiert werde'n, bis der Niederschlag sich noch senkt, wie schon Zaloziecki angibt; am besten aber lälst man dann die Röhrchen ein wenig stehen und zentrifugiert noch einmal, nachdem man das 
Niveau des Eiweißrückstandes genau markiert hat. Ferner ist es gut, die gleiche Bestimmung mit 2 Röhrchen zu gleicher Zeit vorzunehmen und so eines durch das andere zu kontrollieren. Man kann auf solche Weise genau ablesen und Viertelstriche noch richtig bestimmen. Da bei unseren Röhrchen ein Teilstrich $=0,018 \%$ Eiweiß war, so liegen also eventuelle Fehler unter $0,0045 \%$. Sollten im übrigen unserer Methode doch noch Fehler anhaften, was die Feststellung der absoluten Eiweißmenge betrifft, so sei hervorgehoben, daß es sich in unseren Untersuchungen ja mehr darum gehandelt hat, die einzelnen Werte miteinander zu vergleichen und mit anderen relativen Reihen in Beziehung zu setzen. Und daß zu diesem Zweck die so modifizierte Nißlbestimmung vollkommen genügt, zumal wir in jedem Fall ganz gleich verfahren, liegt auf der Hand. Nun zu den Globulinreaktionen. Wir stellten in jedem Falle, soweit unsere Liquormenge genügte, folgende Reaktionen an: vor allem die bekannte Non ne - A pelt - Sch u m msche Phase I, ferner die Buttersäuremethode Noguchis, die Pandysche Reaktion, jene von Braun-Husler, dann in einer geringen Anzahl von Fällen die Probe nach Moritz und die Kla us nersche Reaktion.

Es sei hier der Vollständigkeit halber die Technik dieser Reaktionen beschrieben, zumal sie nicht allgemein bekannt sein dürften und es von Vorteil ist, in einer Arbeit, in der die geübte Technik so wichtig ist, sich eingehend über diese zu verständigen.

Die Noguchi-Reaktion : 0,2 cem der Spinalflüssigkeit wurden mit $1 \mathrm{ccm} 10$ proz. Buttersäure gemischt, bis zum Kochen erhitzt, dann $0,2 \mathrm{ccm}$ einer Normalsodalösung zugesetzt und einige Sekunden gekocht. Nach Mestrezat sind 3 Stunden das Zeitmaximum, in dem eine positive Reaktion aufgetreten sein mul3. Eine später auftretende Opalescenz oder Trübung gilt als negativ.

Die Pandysche Reaktion wird bekanntlich in der Weise ausgeführt, daß man einen Tropfen Liquor in $1 \mathrm{ccm}$ einer 10 proz. Carbolsäurelösung hineinträufeln läßt; der Tropfen ist bei positiver Reaktion clurch milchigweiße Schleierbildung erkennbar. Die Abstufung der positiven Reaktionen haben wir nach der Intensität der Weißfärbung der sich bildenden Wolke bestimmt und mit,+++++ und + bezeichnet, während eine schwach positive Reaktion nach unserer Auffassung dann vorhanden war, wenn beim Einträufeln zwar keine Wolkenbildung vorhanden war, hinterher sich dennoch unverkennbar eine verschieden starke Opalescenz einstellte.

Die Braun-Huslersche Reaktion wurde so ausgeführt, daß zu $21 / 2 \mathrm{ccm}$ einer $\mathrm{n} / 300$ Salzsäurelösung 0,5 Liquor zugesetzt wurden. Nur selten trat eine deutliche Trübung auf; meist war eine nur mehr oder weniger ausgesprochene Opalescenz nachzuweisen und zwar in den meisten Fällen recht bald nach Ansetzen der Probe; in allen zweifelhaften 
Fällen wurde nach den vorgeschriebenen 2 Stunden oder mehr nochmals die Probe kontrolliert.

Die Klausnersche Reaktion wurde teils in der Originalreaktion 0,2 oder 0,3 der zu untersuchenden Flüssigkeit $+0,6$ oder 0,7 Aqu. destillata, nachher mehrere Stunden Brutschrank, teils unter Verwendung höherer Liquormengen ausgeführt.

Es galt nun weiter die Stärke der durch fraktioniertes Aussalzen gefällten Globuline im Liquor festzustellen, eine Aufgabe, die u. W. für den Liquor noch nicht gelöst ist. Spiro und $\mathrm{Fuld}^{2}$ ) haben eine solche Methode für die Trennung des Serumglobulins in Euglobulin und Pseudoglobulin angegeben. Sie brachten das Serum auf eine Sättigung von 28\% Ammonsulfat, durch welche, nach den Feststellungen von Reye, das Fibrinogen und Fibringlobulin gefällt wird, filtrierten $\mathrm{ab}$ und brachten das Filtrat auf eine Sättigung von $33 \%$, der sich $a b$ scheidende Niederschlag stellte das Euglobulin das jene Globulinfraktion in der nach Angabe verschiedener Autoren Immunkörper usw. enthalten sind. Nach weiterer Filtration ließ sich dann ein Globulin, das Pseudoglobulin isolieren, dessen Fällung bei $46 \%$ beendigt ist. Die Fällungsgrenzen sind also nach Re ye, sowie Fuld und S piro für Fibrinogen (und Fibringlobulin) 1,7 resp. 1,9-2,8, für Euglobulin 2,9-3,3, für Pseudoglobulin 3,5-4,6. Für unsere Liquorversuche mußte die Technik verändert werden, denn erstens konnte die Filtration wegen zu geringer Liquormengen nicht vorgenommen werden, zweitens lag in erster Linie daran die gleiche Reaktion bei verschiedenen Fällen durch die Stärke der auftretenden Opalescenz oder Trübung zu unterscheiden, wie es auch die Phase I tut. Wir gingen daher in folgender Weise vor: wir stellten uns in einem Röhrchen Liquor eine 24-28 proz., in einem zweiten eine 33 proz., in einem dritten eine 50 proz. (Phase I) Sättigung mit Ammoniumsulfat (Ammonium sulf. neutr. purissimum. Merck. heiß gesättigt) her und beobachteten die im Verlaufe von einigen Minuten auftretenden Trübungen. Wenn uns nicht genügend Liquor zur Verfügung stand, verwendeten wir folgende Mengen:

$$
\begin{aligned}
& \text { Röhrchen I } 0,24 \mathrm{Amm} \text {. sulf. }+0,76 \text { Liquor } \\
& \text { Röhrchen II } 0,28 \mathrm{Amm} \text {. sulf. }+0,72 \text { Liquor } \\
& \text { Röhrchen III } 0,33 \mathrm{Amm} \text {. sulf. }+0,67 \text { Liquor } \\
& \text { Röhrchen IV } 0,40 \mathrm{Amm} \text {. sulf. }+0,60 \text { Liquor } \\
& \text { Röhrchen V } 0,50 \mathrm{Amm} \text {. sulf. }+0,50 \text { Liquor }
\end{aligned}
$$

sonst die entsprechenden größeren Mengen.

Da diese Röhrchen wegen der verschiedenen Liquormengen nicht miteinander zu vergleichen, sondern gewissermaßen als besondere Reaktionen, welche bei allen Fällen gleich ausgeführt wurden, aufzufassen sind, haben wir in einer Anzahl von Fällen noch aus theoretischen Grün- 
den eine Reihe von Ammoniumsulfuricum-Konzentrationen hergestellt, in denen auch dic Liquormengen die gleichen sind:

Röhrchen I 0,28 Amm. sulf. $+0,50$ Liquor $+0,22 \mathrm{Aq}$. dest.

Röhrchen II 0,33 Amm. sulf. $+0,50$ Liquor $+0,17$ Aq. dest.

Röhrchen III 0,40 Amm. sulf. + 0,50 Liquor + 0,10 Aq. dest.

Röhrchen IV wäre mit Röhrchen $V$ der ersten Reihe identisch. Derselbe Versuch wurde auch mit 1,0 Liquor gemacht.

Wir haben diese letzte Reihe erst aufstellen können, nachdem wir uns überzeugt hatten, daß Hinzufügen von Aqua destillata zum Liquor keine Trübung erzeugt, was später noch genauer zu besprechen sein wirl.

Bevor wir num zu der Technik unserer serologischen Reaktioncn übergehen, sci erwähnt, daß wir in jedem Falle die Zellen in der Fuchs Rosen thalschen Zählkammer gezählt (in besonderem Falle wurde auch ein Trockenpräparat nach (). Fischer oder Alzhei mer gemacht; in der neuen Methode von Durupt sind wir noch in Versuchsstadium). Zur Technik der Zellzählung sei bemerkt, daß uns die Modifikation nach Kaf $\mathrm{ka}^{6}$ ) gute Dienste leistete. Da sie wenig bekannt zu sein scheint, sei sie noch einmal angeführt: Gleich bei der Punktion oder sofort nach derselben werden 10 Tropfen Liquor in ein sorgfältigst gereinigtes kleines Gefäß3 aufgefangen, in dem sich schon ein gleich großer Tropfen der Farblösung befindet. Es wird dann gut geschüttelt und die Zählung kann zu jeder Zeit stattfinden. Diese Methode, die ebenso genau wie die Melangeurtechnik ist, macht das Arbeiten mit dem Melangeur entbehrlich, ist - gleiche Tropfen vorausgesetzt - ebenso genau und verhindert die Degeneration der Zellen, auch wenn die Zellzählung erst lange Zeit nach der Punktion stattfindet.

Auf serologischem Gebiete lag uns vor allem eine einwandfreie Austitrierung des hämolytischen Normalamboceptors und Komplements im Serum und Liquor ob, ferner die Ausführung der W asser m a n nschen Reaktion in beiden Flüssigkeiten unter Anwendung der erlaubten Verfeinerungen.

Die Austitrierung des Normalamboceptors im Blutserum wird von uns, wie schon mehrmals beschrieben, in der einfachen Weise ausgeführt, daß zu fallenden Mengen des inaktiven Serums $1 / 2 \mathrm{cem} 5$ proz. Hammelblutaufschwemmung und $0,05 \mathrm{ccm}$ frisches Komplement zugesetzt und dann mit physiologischer Kochsalzlösung auf $1 \mathrm{ccm}$ aufgefüllt wird (Versuch I). Die Beobachtung gesehieht jede Viertelstunde, wobei die Röhrchen immer geschüttelt werden müssen; die Beurteilung erfolgt am Ende von 2 Stunden. Das Eigenkomplement des Serums wurde in der Weise geprüft (Versuch II), daß die gleichen absteigenden Serummengen wie in Versuch I jedoch natürlich des aktiven Serums mit $1 / 2 \mathrm{ccm} 5$ proz. Hammelblutaufschwemmung versetzt mit physiologischer Kochsalzlösung auf $1 \mathrm{ccm}$ aufgefüllt und wie Versuch $I$ beurteilt wur- 
den. Hatte aber Versuch I ein negatives Ergebnis, waren also im Blut keine Normalamboceptoren vorhanden, so wurde das Komplement mit Immunamboceptor nachgewiesen, indem zu absteigenden Mengen des inaktiven Serums $1 / 2 \mathrm{~cm}$ der lösenden Amboceptordosis und $1 / 2 \mathrm{ccm} 5$ proz. Hammelblutkörperchen gegeben und auf $2 \mathrm{ccm}$ aufgefüllt wurde.

Die Bestimmung des Normalamboceptors im Liquor ist an diesem Orte schon eingehend geschildert worden. Wir können nur raten, die Technik möglichst genau nachzuahmen. Im Falle, daß $10 \mathrm{ccm}$ nicht zur Verfügung stehen, können auch $5 \mathrm{ccm}$ mit $1 / 2 \mathrm{ccm} 5$ proz. Hammelblut verwendet werden; tiefer soll aber bei Reaktion der Liquormengen nicht gegangen werden, wenn nicht, wie Boas und $\mathrm{Neve}^{1}$ ) es getan haben, nach unten titriert wird. Modifikationen, wie sie Zaloziecki mit der Methode vorgenommen hat, sind nicht statthaft. Auffallend sind bei Zaloziecki auch die hohen verwendeten Komplementdosen $0,08-0,1$, während wir fast immer bei Anwendung voln $10 \mathrm{ccm}$ Liquor nur 0,03-0,05 Komplement verwenden. Vom Komplementsvorversuche, der unbedingt notwendig ist, ist in der ganzen Publikation Zaloziec kis kein Wort enthalten. Es ist auch nicht zu empfehlen, wie Zaloziecki es getan hat, manche Liquores lange Zeit ,,mehrere Wochen" lagern zu lassen, bevor die Reaktion gemacht wird. Wer sich näher mit der Reaktion beschäftigt hat, weiß, wie viel Fehlerquellen durch ungenaues Arbeiten entstehen können; es ist daher einleuchtencl, zu wieviel Fehlresultaten Nachprüfungen führen, die dic Methode an allen Enden modifizieren wollen.

Es sei daher unsere Methodik nochmals wiederholt: zu $10 \mathrm{ccm}$ des absolut blutfreien, klaren und farblosen Liquors wird $1 \mathrm{ccm} 5$ proz. Hammelblutaufschwemmung gegeben und gut geschüttelt, hierauf zwei Stunden im Brutschranke gelassen, wobei darauf gesehen werden muß, daß von Zeit zu Zeit geschüttelt wird. Während dieser Zeit ist darauf zu achten, ob keine Klärung, welche die Lösung der Blutkörperchen anzeigen würde, eintritt. Nach Ablauf der 2 Stunden ist scharf zu zentrifugieren, bis die überstehende Flüssigkeit ganz klar ist; man muß nun darauf achten, ob die klare Flüssigkeit gelblich (siehe unten) geworden ist oder ihre Farblosigkeit beibehalten hat. Nun wird der Liquor abgegossen (bei gutem Abgießen läßt er sich zur Wasser man nschen Reaktion sehr gut verwenden), Kochsalzlösung bis zur Marke $1 \mathrm{ccm}$ (bei $5 \mathrm{ccm}$ Liquor und 0,5 ccm Hammelblut bis zur Marke 0,5) zugesetzt, g u t durchgemischt und $0,5 \mathrm{~cm}$ in je ein Röhrchen gegeben. Es kommen nun die vorher austitrierten Komplementmengen hinzu; wenn man das frische Komplement mit konzentrierter Hammelblutlösung versetzt und sofort scharf zentrifugiert, kann man einen guten Teil der Normalamboceptoren des Komplements an die roten Blutkörperchen binden und ist dann in der Lage, größere Komplementmengen zu den mit Liquor 
sensibilisierten Hammelblutkörperchen hinzuzusetzen. Vom Komplementversuch wählt man geeignetermaßen jene Mengen, bei denen noch eine Spur oder keine Lösung mit 0,5\% Hammelblut aufgetreten ist. Nach drei Stunden Thermostat erfolgt die Ablesung. Der Komplementgehalt des Liquors zeigt sich im Auftreten vor Hämolyse während der Sensibilisierung, in schwächeren Graden durch Gelb- oder Gelblichfärbung der beim Zentrifugieren überstehenden Flüssigkeit. Die Prüfung auf Komplement mit Immunamboceptor (wir verwendeten 0,5 Liquor $+0,5$ mehrfach sensibilisierter 5 proz. Hammelblutaufschwemmung), zeigt keine wesentlichen Differenzen gegenüber der oben beschriebenen Bestimmungsart; sie hat nur den einen Vorteil, daß sich die Komplementmenge quantitativ fixieren läßt. Wir haben auch noch nie beobachten können, daß in einem Liquor nur Komplement, aber kein Normalamboceptor vorkommt, wie es im Blute der Fall sein kann. Hier sei übrigens gleich bemerkt, daß die von Zaloziecki angewendeten so geringen Mengen Hammelblutes $(0,05)$ nicht statthaft sind, weil hier der Liquor bei Verwendung so hoher Amboceptoren imstande ist Lösungen hervorzurufen, die nicht auf Komplementgehalt beruhen, wie Zaloziecki selbst gefunden hat. Wir konnten bei unserer Versuchsanordnung niemals derartige Lösungen konstatieren. Es ist daher nicht verständlich, wie Zaloziecki aus seiner Versuchsanordnung so weitgehende Folgerungen ziehen konnte.

Natürlich muß hier hervorgehoben werden, daß selbst ein stark positiver Ausfall der Hämolysinreaktion bei der Paralyse noch immer eine viel geringere Menge von Normalamboceptor darstellt, als eine starke hämolytische Reaktion des inaktiven Blutserums; Untersucher, die austitriert haben, fanden noch eine stark positive Hämolysinreaktion nur in sehr seltenen Fällen bei 0,25 Liquor, während bei starkem Normalamboceptorgehalt im Serum meist 0,01 noch komplett hämolvtisch wirken. Wir haben daher im Verlaufe unserer Untersuchungen Beziehungen eingeführt, die dem zahlenmäßigen Verhältnis gerecht werden. Für das Komplement gestalten sich die Verhältnisse ähnlich; sie sind noch schwerer zahlenmäßig auszudrücken.

Wir haben im Verlaufe unserer Untersuchungen auch das aus der Vene tropfende Blut direkt in den frischen Liquor aufgenommen, um die Hämolysin- und Komplementreaktion eines solchen Liquors nach verschiedenen Zeichen zu studieren, den wir artifiziell bluthaltig gemacht hatten. Darüber im nächsten Teile.

Die Wassermannsche Reaktion führten wir mit allen in unserem Laboratorium üblichen Kautelen und Verfeinerungen aus. So wurden steigende Serumkonzentrationen, wenn nötig eingestellt, wurde das aktive Serum in jedem Falle geprüft (Modifikation nach Stern), wurde die Normalamboceptorabsorption des Patientenserums in der Kälte 
und die Baryumsulfatmethode nach Wechsel man n ausgeführt. Ferner wurde auch $J$ acobsthals Cholesterinkältemethode in Verwendung gezogen. Auf solche Weise suchten wir zu serologisch einwandfreien Resultaten zu gelangen, indem wir in zweifelhaften Fällen immer nur dann eine positive Reaktion gelten ließen, die zwei der Modifikationen in genügender Stärke gezeigt hatten. Im Liquor wurde die Auswertungsmethode nach Hauptmann in jedem Falle vorgenommen.

Utber sonstige Reaktionen, die in jedem Falle gemacht wurden, deren Resultate aber nicht in direktem Zusammenhange mit dem Thema diescr Arbeit stand, wie die Langesche Goldsolreaktion, die Wohlgemuth sche Fibrinogen- und Fibrinfermentbestimmung, wird anderen Ortes berichtet werden.

\section{Material und Ergebnisse.}

Unter Anwendung der oben eingehend erörterten Untersuchungstechnik haben wir nun ein Material untersucht, das aus über 150 Fällen besteht. Den Kern dieses Materials bilden 100 Paralysen, da wir bei diesen in erster Linie uns über die erörterten Fragen Sicherheit verschaffen wollten. Es seien deshalb unsere Untersuchungsergebnisse über die Paralysen an erster Stelle mitgeteilt.

I.

Von den 100 klinisch sicheren Paralysen wurde einer zweimal punktiert; der Liquor war in allen untersuchten Fällen frei von frischem Blut, dreimal war er xanthochrom, aber klar. Was die Gesamteiweißbestimmung betrifft, so sei etwas genau darauf eingegangen, weil sich ebenso wie für die für den normalen Liquor geltenden Zahlen auch in jenen für die Paralyse sehr große Differenzen bei den verschiednen Autoren finden. Wir wollen nur zwei Zahlen der jüngsten Zeit herausgreifen: Plaut, Rehm und Schottmüller ${ }^{12}$ ) nehmen $0,045 \%$ als Durchschnittseiweißgehalt der Paralysen an, während Zaloziecki18) von $0,2 \%$ spricht! Von unserem Material fallen vier Fälle weg, da bei zwei die Bestimmung des Cesamteiweißes unterblieben, bei zwei nach der A ufrechtschen Methode unternommen worden war. Nach unserer verfeinerten Nissl methode wurden also 96 Paralysen (einer zweimal) untersucht. Es ergaben sich die in Tabelle I aufgeführten Zahlen. In unseren Fällen hat also keiner die Zahl von $2 \%$, wie sie Zaloziecki angibt, erreicht, ja $1 \%$ ist selten. Wir müssen daher Pla u t, Reh m und Schottmüllers Angabe bestätigen. Bezüglich der Pleocytose ergaben sich keine Besonderheiten, jedenfalls keine engeren Beziehungen zu den anderen Reaktionen. Es sei hier auch gleich hervorgehoben, daß die 28 proz. Sättigung des Liquors mit Ammoniumsulfat bei Verwendung kleinerer oder größerer Liquormengen nie eine Spur von 
Trübung oder Opalescenz hervorbrachte. Es muß hier noch besonders betont werden, daß bei Anstellung dieser Reaktion immer stark geschüttelt werden muß und daß ähnlich wie bei der Phase I Reaktion erst nach mehreren Minuten abgelesen werden soll. Auch muß auf eine gute Beschaffenheit der Ammoniumsulfuricumlösung geachtet werden. Ge-

Tabelle I. Gesamteiweißgehalt

\begin{tabular}{|c|c|c|c|}
\hline & \multicolumn{2}{|l|}{ Menge } & \multirow{2}{*}{$\begin{array}{c}\text { Fälle } \\
15\end{array}$} \\
\hline unter & ... & $0,02 \%$ & \\
\hline uber & . . . . & $0,02 \%$ & 10 \\
\hline über & . . . . & $0,03 \%$ & 23 \\
\hline über & . . . . & $0,01 \%$ & 10 \\
\hline über & . . . . & $0,05 \%$ & 20 \\
\hline über & . . . . & $0,06 \%$ & 12 \\
\hline über & .... & $0.07 \%$ & 3 \\
\hline über & . . & $0,09 \%$ & 3 \\
\hline über & . . . . & $0,1 \%$ & 1 \\
\hline \multirow[t]{2}{*}{ nach } & Aufrecht & $0,1 \%$ & 2 \\
\hline & & sa & 99 \\
\hline
\end{tabular}

genüber Zaloziecki18) sei betont, daß wir bei unseren Paralysefällen weder frisch noch nach längerem Stehen die Bildung irgendwelcher Gerinnsel beobachten konnten, wenn der Liquor vollkommen blutfrei war. War aber eine wenn auch nur geringe oder nur eine Portion betreffende Blutbeimengung vorhanden, dann konnten manchmal die Bil-

Tabelle II.

Hämolytisches Verhalten des Paralytikerserums.

\begin{tabular}{c|c|c|c|c|c|c|c|c|c}
\hline \hline \multicolumn{3}{c}{ Normalamboceptor } & \multicolumn{3}{c|}{ Komplement } & \multicolumn{3}{c}{ Beides } \\
\hline+ & Spur & 0 & + & Spur & 0 & + & Spur & 0 \\
\hline 60 & 23 & 6 & 65 & 14 & 9 & $\underbrace{5}_{6 \%}$ & 3 \\
$67 \%$ & $26 \%$ & $7 \%$ & $76 \%$ & $15 \%$ & $9 \%$ & & $\frac{3 \%}{11 \%}$
\end{tabular}

* Diese Zahl bedeutet, in wieviel Fällen eine Spur der einen Reaktion, eine negative der andern entsprach.

dung kleiner Fibrinfädchen beobachtet werden. Die Anstellung der Klausnersehen Reaktion ergab in keinem der Fälle ein positives Resultat. Bezüglich des hämolytischen Verhaltens des Blutserums wäre gleich vorwegzunehmen, daß wie Tabelle II sagt, wir in einer ganz ansehnlichen Anzahl von Fällen eine Herabsetzung bis Aufhebung derselben fanden; freilich erreichte die Prozentanzahl der Fälle bei denen 
Normalamboceptor oder Komplement fehlte, nicht die früher angegebene Höhe (7). Wir wollen nun weiter in Tabelle III die Bezieh ungen des Gesamteiweißgehaltes zu den einzelnen Eiweißreaktionen wiedergeben. In der ersten Rubrik befinden sich die Zahlen für den Gesamteiweißgehalt in Prozenten steigend angeordnet, in den anderen Rubriken die verschiedenen Reaktionen. Auf den ersten Blick muß auffallen, daß von einem Parallellismus zwischen Gesamteiwei $\beta$ und Globulinreaktionen nicht zu sprechen ist; er ist nur in ganz groben Zügen gegeben indem die starken Reaktionen bei höherem Eiweißgehalt häufiger sind. Eher zeigt sich ein gewisser Parallelismus zwischen den einzelnen Globulinreaktionen selbst, der aber oft durchbrochen wird. Die Bra un - $\mathrm{H}$ uslersche Reaktion nimmt eine Sonderstellung ein, wir fanden sie 51 mal unter 80 Paralysefällen positiver. Uber die diagnostische Brauchbarkeit dieser Reaktion und ihren theoretischen Wert werden wir erst reden können, bis wir auch über die Nichtparalysen berichtet haben. Das gleiche gilt für eine vergleichende Statistik über den praktischen Wert der anderen Reaktionen, wenn auch hier schon hervorgehoben werden muß, daß unter den Paralysen die Pand ysche Reaktion häufig den stärksten Ausschlag zeigt, dann die von Noguchi, zum Schlusse erst die Phase I. Freilich ist diese aber auch bei dem geringsten Gesamteiweißwert (Fall 32) doch positiv.

Tabelle III. Paralyse.

Beziehungen zwischen (iesamteiweißgehalt und verschiedenen Eiweißreaktionen.

\begin{tabular}{|c|c|c|c|c|c|}
\hline $\begin{array}{l}\text { Fall } \\
\text { Nr. }\end{array}$ & $\begin{array}{c}\text { Gesamteiweib } \\
\text { in } \%\end{array}$ & Phase I & Pandy & Noguchi & Braun-Husler \\
\hline 32 & 0,009 & -1. & $-1+$ & +-+ & $\theta$ \\
\hline 39 & 0,0135 & - & $\frac{1}{i}$ & 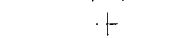 & $\theta$ \\
\hline$\tilde{5}$ & 0,018 & ++ & $t+$ & $-t$ & $\theta$ \\
\hline 16 & 0,018 & + & $+t$ & $+-t$ & Opal. \\
\hline 19 & 0,018 & $\operatorname{sch} w .+$ & $\theta$ & $\theta$ & $\theta$ \\
\hline 21 & 0,018 & $+\cdot$ & $t$ & schw. 十 & Opal. \\
\hline 30 & 0,018 & $+\frac{1}{i}$ & $+t$ & + & $\theta$ \\
\hline 35 & 0,018 & $t+$ & $+t$ & +-++ & schw. Opal. \\
\hline 36 & 0,018 & Opal. & $\operatorname{sch} w .+$ & $\theta$ & $\theta$ \\
\hline 51 & 0,018 & + & $\frac{1}{i}+$ & -1 & schw. Opal. \\
\hline .52 & 0,018 & ++ & $-i \cdot+$ & $-t+t$ & Opal. \\
\hline 61 & 0,018 & $+\frac{1}{1}+$ & +-1 & $+4+$ & Opal. \\
\hline 29 & 0,0225 & + & + & + & Trübung \\
\hline 63 & 0,0225 & $-1-+$ & $-t+$ & ++ & deutl. positiv \\
\hline 13 & 0,027 & + & + & + & \\
\hline 15 & 0,027 & $+t$ & $-t+$ & $+t$ & Spur Opal. \\
\hline 40 & 0,027 & Opal. & + & + & $\theta$ \\
\hline 44 & 0,027 & $\frac{1}{1}$ & $\frac{1}{1}+$ & -+-+ & \\
\hline 54 & 0,027 & $\therefore-\frac{1}{5}$ & $\div+$ & $t-t$ & Opal. \\
\hline 57 & 0,027 & $i$ & $i \div$ & $\because !-\frac{1}{1}$ & \\
\hline
\end{tabular}


Über neuere Eiweißreaktionen der Spinalflüssigkeit.

(Fortsetzung von Tabelle III.)

\begin{tabular}{|c|c|c|c|c|c|}
\hline $\begin{array}{c}\text { Fall } \\
\text { Nr. }\end{array}$ & $\begin{array}{l}\text { Gesamteiwei } \beta \\
\text { in } \%\end{array}$ & Phase I & Pandy & Noguchi & Braun-Husler \\
\hline 72 & 0,027 & + & ++ & + & Opal. \\
\hline 75 & 0,027 & $\dot{t}$ & $+\div$ & $\frac{1}{i}$ & Opal. \\
\hline 50 & 0,0315 & - & $t+$ & \pm & $\theta$ \\
\hline 56 & 0,0315 & + & $++t$ & ++ & Spur Opal. \\
\hline 65 & 0,0315 & + & + & ++ & schw. Opal. \\
\hline 66 & 0,0315 & ++ & +++ & $+t$ & Opal. \\
\hline 67 & 0,0315 & $+t$ & $+t+$ & $+\dot{+}$ & $\theta$ \\
\hline 6 & 0,036 & + & ++ & -1 & schw. Opal. \\
\hline 7 & 0,036 & + & $-t+$ & + & $\theta$ \\
\hline 14 & 0,036 & $-t$ & + & + & \\
\hline 18 & 0,036 & $+t$ & $t+$ & + & + \\
\hline 22 & 0,036 & + & ++ & ++ & schw. Opal. \\
\hline 24 & 0,036 & schw..+ & + & + & deutl. Opal. \\
\hline 26 & 0,036 & + & + & + & $\theta$ \\
\hline 27 & 0,036 & $+-t$ & $t+$ & + & $\theta$ \\
\hline 31 & 0,036 & + & + & $\dot{\tau}$ & $\theta$ \\
\hline 34 & 0,036 & $+\cdot+$ & +++ & -+ & $\theta$ \\
\hline 37 & 0,036 & + & + & + & $\theta$ \\
\hline 38 & 0,036 & $+t$ & ++ & $+t$ & $\theta$ \\
\hline 42 & 0,036 & $t+$ & $++t$ & $+t$ & \\
\hline 43 & 0,036 & + & ++ & $+t$ & $\theta$ \\
\hline 45 & 0,036 & ++ & $+i$ & + & $\theta$ \\
\hline 62 & 0,036 & +1 & $+t$ & $t+t$ & Opal. \\
\hline 100 & 0,036 & + & + & + & $\theta$ \\
\hline 83 & 0,042 & + & ++ & & Opal. \\
\hline 8 & 0,045 & $+t$ & + & + & Opal. \\
\hline 9 & 0,045 & $+t$ & + & + & Opal. \\
\hline 12 & 0,045 & $\div$ & $+t$ & ++ & $\theta$ \\
\hline 23 & 0,045 & + & ++ & ++ & $\operatorname{sch} w .+$ \\
\hline 25 & 0,045 & $+5 !$ & $+t$ & $t+$ & \\
\hline 41 & 0,045 & $-1+\frac{1}{1}$ & $++t$ & $+t+$ & $\theta$ \\
\hline 53 & 0,045 & $t+t$ & $+t+$ & +++ & deutl. Opal. \\
\hline 73 & 0,045 & $+t$ & $+t+$ & +++ & Opal. \\
\hline 76 & 0,045 & $+i$ & $t+t$ & $++t$ & Opal. \\
\hline 70 & 0,0515 & $++t$ & +++ & $+t+$ & schw. Opal. \\
\hline 68 & 0,0515 & +++ & +++ & +++ & Opal. \\
\hline 10 & 0,054 & $+t$ & ++ & & $\theta$ \\
\hline 11 & 0,054 & ++ & ++ & $+t$ & $\theta$ \\
\hline 20 & 0,054 & ++ & $+-t$ & +1 & schw. Opal. \\
\hline 21 & 0,054 & +1 & $+t$ & $t+$ & $\theta$ \\
\hline 33 & 0,054 & $+-t$ & ++ & + & $\theta$ \\
\hline 48 & 0,054 & +++ & $t+$ & $+t$ & Opal. \\
\hline 49 & 0,054 & ++ & ++ & + & $\theta$ \\
\hline 55 & 0,054 & $t+-$ & $+t+$ & $t+t$ & Opal. \\
\hline 58 & 0,054 & 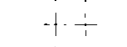 & $+t+$ & $++t$ & Opal. \\
\hline 74 & 0,054 & $+1-$ & +++ & $+1+t$ & Opal. \\
\hline 78 & $0,0 . \overline{4}$ & ++ & $++t$ & $+t+$ & Opal. \\
\hline 81 & 0,054 & -1 & $+t$ & ++ & Opal. \\
\hline
\end{tabular}


(Fortsetzung von Tabelle III.)

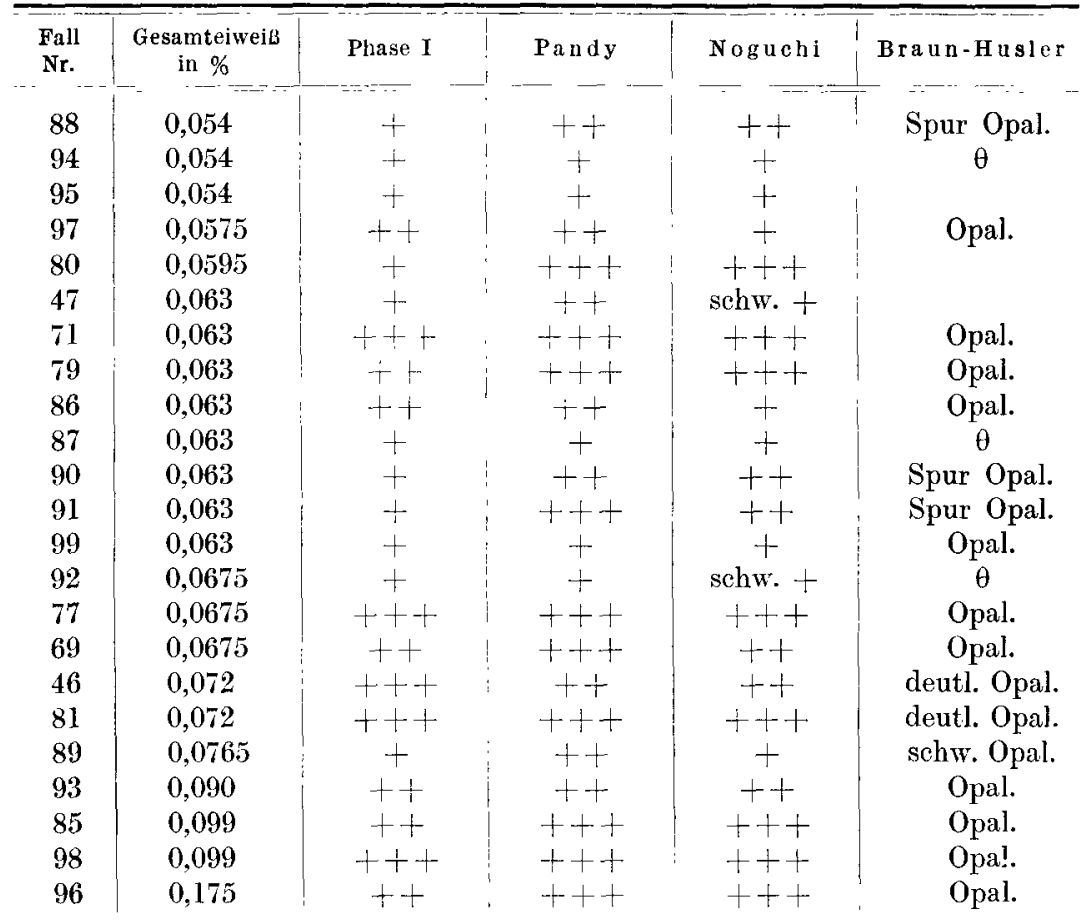

Wir wollen nun dazu übergehen, festzustellen, welche Bezieh ungen zwischen dem Gesamteiweißgehalt des Liquors und seinem Gehalt an Normalamboceptoren und Komplement bestehen. Wir wenden dabei in den diesbezüglichen Tabellen der guten Utbersicht halber folgende Bezeichnungen an: ein ganz besonders starkes Gehalt an Normalamboceptoren im Liquor $(++++)$ wird mit 10, ein sehr starkes $(+++)$ mit 8 , ein starkes $(++)$ mit 6 , ein mittelstarkes $(+)$ mit 4, ein schwach positives $( \pm)$ mit 3 , Spur-Lösung mit 2 bezeichnet. Ein gleiches gilt für die Komplementmengen. Für den Normalamboceptor im Blute setzen wir dementsprechend die folgenden Zahlen:

$$
\begin{array}{r}
++++=500 \\
+++=400 \\
++=300 \\
+=200 \\
\pm=150 \\
\mathrm{sp}=100
\end{array}
$$

Prinzip ist: im Liquor gehen wir aus von $10 \mathrm{ccm}+1 \mathrm{ccm}$ Hammelblut, im Blut von $0,1 \mathrm{ccm}+1 / 2 \mathrm{ccm}$ Hammelblut; also zeigen die gleichen Hämolysegrade einen Amboceptorenreichtum an, der im Serum 50 mal größer ist. Durch die Einführung dieser Zahlen glauben wir es auch 
möglich gemacht zu haben, ein wirklichcs Bild dєs Amboceptorendurchtrittes gegeben zu haben, indem wir Zahlen bilden können, in denen der Serumtiter den Nenner, der Titer im Liquor den Zähler bildet, so z. B. in Fall 5 ist der Úbertritt $8 / 200=1 / 25$, in Fall 62 ist der wirkliche Utbergang $4 / 100=1 / 25$, also ebenso groß, während in Kreuzen angegeben die beiden Stärken + und +++ wären. Betrachten wir nun Tabelle IV so müssen wir sagen, daß innerhalb der Paralyse sich ein Parallelismus zwischen Übertritt an Amboceptoren und Eiweiß nicht stiften läßt. In den 12 ersten Fällen mit ganz sicher nicht erhöhtem Gasamteiweißgehalt finden wir 9 mal Amboceptoreübergang und zwar $1 / 20,1 / 100,1 / 200,1 / 50,1 / 100,1 / 50,1 / 50$ (in Fall 21, 51, 29 fehlt die Blutuntersuchung); in den 12 letzten Fällen mit dem Gesamteiweißgehalt von $0,063 \%$ bis $0,175 \%$ ist Normalamboceptorübergang ebenfalls 9 mal zu konstatieren und zwar in den Stärken: 1/50,1/50,1/25, 1/20, $1 /{ }_{40}, 1 / 50,1 / 150$, also kaum ein Unterschied gegenüber den erstgenannten Fällen.

Was den Komplementübergang betrifft, so gilt dasselbe: bei einem Eiweißgehalt von 0,027 finden wir die Übergangszahl von 1/50, bei 0,0315 : $1 / 40$, bei $0,036: 1 / 40$ und $1 / 50$, bei $0,054: 1 / 50,1 / 50$.

Es läßt sich also zwischen Höhe des Gesamteiweißgehaltes und Normalamboceptor resp. Komplementgehalt der Spinalflüssigkeit innerhalb der Paralysen kein auch nur in groben Zügen vorhandener Parallelismus feststellen.

Wir wollen nun weiter darangehen, die eventuellen Bezieh ungen zwischen den durch verschiedenes Aussalzen dargestellten Globulinfraktionen (die Phase I eingerechnet) mit dem Normalamboceptor und Komplementgehalt der Spinalflüssigkeit darzustellen. Dies ist in Tabelle $V$ enthalten. Für die Immunstoffe des Blutes und des Liquors sind dieselben Zahlen gewählt wie in Tabelle IV. Wir er. sehen aus der Tabelle, daß bei 33 prozentiger Sättigung mit Ammoniumsulfat im Liquor meist schon eine leichte Ausfällung eintritt, daß also die sog. Euglobulinfraktion in der Spinalflüssigkeit vorhanden ist. In Fall 36 ist nun diese Fraktion $\theta$, der Amboceptorübergang $1 / 100$, in Fall $631 / 50$; Opalescenz bei 33 prozentiger Sättigung kann mit $1 / 100$ (Fall 1), 1/50 (Fall 3), 1/80 (Fall 24) usw. Antikörperübergang verbunden sein; eine + Euglobulinfraktion zeigt sich bei 1/50 (Fall 4), 1/30 (Fall 5), $1 / 25$ (Fall 10), 1/200 (Fall 16) usw., Amboceptorstärke im Liquor; bei ++ starker 33 proz. Sättigung finden wir 1/30 (Fall 34), 1/50 (Fall 35), während die +++ starke Euglobulinfraktion in Fall 46 trotz genügend hohen Scrumtiters nicht zum Ubertritt von Normalamboceptoren gefihrt hat. Der leichte Parallelismus, der sich aus der Betrachtung einzelner dieser Zahlen ergibt, ist bei Vergleich der 40 proz. sog. Pseudoglobulinfraktion mit dem Amboceptorübergang noch geringer und die 
Tabelle IV.

Beziehungen zwischen Gesamteiweiß und Amboceptor resp. Komplementgehalt.

\begin{tabular}{|c|c|c|c|c|c|c|c|c|c|c|c|}
\hline \multirow{2}{*}{ 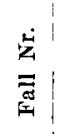 } & \multirow{2}{*}{$\begin{array}{l}\text { Gesamt- } \\
\text { eiwelB } \\
\text { in } \%\end{array}$} & \multicolumn{2}{|c|}{$\begin{array}{c}\text { Normal- } \\
\text { amboceptor }\end{array}$} & \multicolumn{2}{|c|}{$\begin{array}{l}\text { Kom- } \\
\text { plement }\end{array}$} & \multirow{2}{*}{$\begin{array}{l}\not{n} \\
\ddot{Z} \\
\vec{z}\end{array}$} & \multirow{2}{*}{$\begin{array}{c}\text { Gesamt- } \\
\text { eiweib } \\
\text { in } \%\end{array}$} & \multicolumn{2}{|c|}{$\begin{array}{c}\text { Normal- } \\
\text { amboceptor }\end{array}$} & \multicolumn{2}{|c|}{$\begin{array}{c}\text { Kom- } \\
\text { plement }\end{array}$} \\
\hline & & Blut & Liquor & Blut & Liquor & & & Blut & Liquor & Blut & Liquor \\
\hline 39 & 0 & 300 & $A$ & 400 & $A$ & 0 & 5 & $\theta$ & $f 4$ & $f$ & \\
\hline 39 & 0,0135 & 100 & $\theta$ & $\begin{array}{l}400 \\
300\end{array}$ & $\theta$ & 12 & $\begin{array}{l}0,043 \\
0,045\end{array}$ & $\begin{array}{r}\theta \\
900\end{array}$ & $\begin{array}{r}14 \\
\theta\end{array}$ & $\begin{array}{r}\mathrm{I} \theta \\
900\end{array}$ & $\theta$ \\
\hline 5 & 0,018 & 200 & 8 & 300 & $\theta$ & 23 & 0,045 & 300 & 4 & $\begin{array}{l}200 \\
200\end{array}$ & $\theta$ \\
\hline 16 & 0,018 & 400 & 2 & 200 & $\theta$ & 25 & 0,045 & 400 & 8 & 400 & $\theta$ \\
\hline 19 & 0,018 & 400 & 4 & 400 & 0 & 41 & 0,045 & 100 & 8 & 100 & $\theta$ \\
\hline 21 & 0,018 & & 4 & & $\theta$ & 53 & 0,045 & 300 & 6 & 300 & $\theta$ \\
\hline 30 & 0,018 & $\theta$ & $\theta$ & $\theta$ & $\theta$ & 73 & 0,045 & 300 & 2 & 150 & $\theta$ \\
\hline 35 & 0,018 & 300 & 6 & 100 & $\theta$ & 76 & 0,045 & 400 & 6 & 100 & $\theta$ \\
\hline 36 & 0,018 & 400 & 4 & 300 & $\theta$ & 70 & $0,051 \tilde{5}$ & 200 & 6 & 100 & $\theta$ \\
\hline 51 & 0,018 & & 4 & & $\theta$ & 68 & $0,0 \check{15}$ & 100 & 4 & 300 & $\theta$ \\
\hline 52 & 0,018 & 400 & 8 & 400 & $\theta$ & 10 & $0,0 \overline{34}$ & 100 & 4 & 100 & 2 \\
\hline $6 \mathrm{I}$ & 0,018 & 400 & 8 & 100 & $\theta$ & $11^{\prime}$ & 0,054 & f 400 & 8 & 300 & $\theta$ \\
\hline 29 & 0,0225 & & 8 & & 0 & 20 & 0,054 & 400 & 4 & 400 & $\theta$ \\
\hline 63 & 0,0225 & 400 & 8 & 300 & $\theta$ & 21 & 0,054 & & 4 & & $\theta$ \\
\hline 13 & 0,027 & 200 & 2 & 200 & $\theta$ & $33 !$ & 0,054 & 300 & 6 & 400 & $\theta$ \\
\hline 15 & 0,027 & 400 & 8 & 300 & 2 & 48 & 0,054 & 400 & 6 & 400 & $\theta$ \\
\hline 40 & 0,027 & 200 & 4 & 300 & $\theta$ & 49 & 0,054 & 100 & 4 & 300 & $\theta$ \\
\hline 44 & 0,027 & & & & $\theta$ & $55^{i}$ & 0,054 & 400 & 4 & 300 & $\theta$ \\
\hline 54 & 0,027 & 100 & 2 & 300 & $\theta$ & 58 & $0,0 \tilde{5} 4$ & 300 & 8 & 400 & 8 \\
\hline 57 & 0,027 & 200 & 6 & 400 & $\theta$ & 74 & 0.054 & f 400 & 8 & 400 & $\theta$ \\
\hline 72 & 0,027 & k 100 & 2 & $\theta$ & $\theta$ & 78 & 0,054 & 400 & 6 & 400 & $\theta$ \\
\hline 75 & 0,027 & 150 & $\theta$ & 200 & $\theta$ & 84 & 0,054 & 200 & $\theta$ & 200 & $\theta$ \\
\hline 50 & 0,0315 & 400 & 8 & 400 & $\theta$ & 88 & 0,054 & 100 & 4 & 400 & $\theta$ \\
\hline 56 & 0,0315 & 100 & 2 & 300 & $\theta$ & $94^{\prime}$ & 0,054 & 100 & 2 & 100 & $\theta$ \\
\hline 65 & 0,0315 & 400 & 8 & 300 & 8 & $95^{1}$ & 0,054 & 400 & 8 & 400 & $\theta$ \\
\hline 66 & 0,0315 & 300 & 8 & 100 & $\theta$ & 97 & 0,0575 & 100 & 2 & 300 & $\theta$ \\
\hline 67 & $0,031 \tilde{3}$ & 400 & 8 & 400 & $\theta$ & 80 & 0,0595 & 400 & 6 & 400 & $\theta$ \\
\hline $6^{\mid}$ & 0,036 & 400 & 8 & 400 & $\theta$ & 47 & 0,063 & 300 & & 400 & $\theta$ \\
\hline 7 & 0,036 & 100 & 2 & 100 & $\theta$ & 71 & $0,06: 3$ & 200 & $\theta$ & 300 & $\theta$ \\
\hline 14 & 0,036 & & f 4 & 100 & $\theta$ & 79 & 0,063 & $\theta$ & 8 & 100 & $\theta$ \\
\hline 18 & 0,036 & & 4 & & $\theta$ & 86 & 0,063 & 200 & 6 & 100 & $\theta$ \\
\hline 22 & 0,036 & 400 & 8 & 400 & $\theta$ & 87 & 0,063 & 100 & 8 & $\theta$ & $\theta$ \\
\hline 24 & 0,036 & 300 & 4 & 300 & $\theta$ & 90 & 0,063 & 100 & 2 & $\theta$ & $\theta$ \\
\hline 26 & 0,036 & 400 & 4 & 400 & $\theta$ & 91 & 0,063 & 400 & $\theta$ & 200 & $\theta$ \\
\hline 27 & 0,036 & $f \theta$ & $\theta$ & $\theta$ & $\theta$ & 99 & 0,063 & 100 & 2 & $\theta$ & $\theta$ \\
\hline 31 & 0,036 & 400 & 8 & 300 & 8 & 92 & 0,063 & 100 & $\theta$ & $\theta$ & $\theta$ \\
\hline 34 & 0,036 & 200 & 8 & 400 & 8 & 77 & 0,0675 & 100 & 4 & 200 & $\theta$ \\
\hline 37 & 0,036 & 100 & & 200 & $\theta$ & 69 & $0,067 \tilde{\jmath}$ & 150 & 8 & 100 & $\theta$ \\
\hline 38 & 0,036 & f 400 & 8 & 400 & $\theta$ & 46 & 0,072 & 400 & f 6 & f 100 & $\theta$ \\
\hline 42 & 0,036 & & & & $\theta$ & 89 & 0,0765 & - & $\theta$ & $\cdots$ & $\ldots$ \\
\hline 43 & 0,036 & & & & $\theta$ & 83 & 0,090 & 300 & 8 & 300 & $\theta$ \\
\hline $45_{i}$ & 0,036 & 200 & 2 & 200 & $\theta$ & 85 & 0,099 & 400 & f 8 & 400 & $\theta$ \\
\hline 62 & 0,036 & 100 & 4 & 100 & $\theta$ & 98 & 0,099 & 300 & 2 & 400 & $\theta$ \\
\hline 100 & 0,036 & 300 & 4 & $\theta$ & $\theta$ & 96 & 0.175 & - & 8 & - & $\theta$ \\
\hline 83 & 0,042 & 300 & 8 & 300 & $\theta$ & & & & & & \\
\hline
\end{tabular}


Tabelle V.

Beziehungen zwischen den Globulinfraktionen und dem Normalamboceptor resp. Komplementgehalt.

\begin{tabular}{|c|c|c|c|c|c|c|c|c|}
\hline \multirow{2}{*}{ 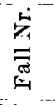 } & \multicolumn{4}{|c|}{ Ammoniumsulfatsättigung } & \multicolumn{2}{|c|}{$\begin{array}{c}\text { Normal- } \\
\text { amboceptor }\end{array}$} & \multicolumn{2}{|c|}{ Komplement } \\
\hline & $24 \% 28$ & $: 3 \%$ & $40 \%$ & $50 \%$ & Blut & Eiquor & Blut & Liquor \\
\hline 1 & $\theta$ & deutl. Opal. & $+t$ & $+t+$ & 200 & 2 & f 200 & $\theta$ \\
\hline 2 & $\theta$ & + & $t+$ & $++t$ & & 8 & & $\theta$ \\
\hline 3 & $\theta$ & Opal. & $t+$ & $+t$ & 100 & 8 & 400 & 8 \\
\hline 4 & $\theta$ & + & + & + & 400 & 8 & 400 & $\theta$ \\
\hline 5 & $\theta$ & + & $t+$ & $+t$ & 200 & 8 & 300 & $\theta$ \\
\hline 6 & $\theta$ & Opal. & ++ & + & 400 & 8 & 400 & $\theta$ \\
\hline 7 & $\theta$ & + & $t+$ & + & 100 & 2 & 100 & $\theta$ \\
\hline 8 & $\theta$ & + & $t+t$ & $+t$ & & 8 & & 2 \\
\hline 9 & $\theta$ & Opal. & ++ & $+t$ & $\theta$ & $\mathrm{f} 4$ & f $\theta$ & $\theta$ \\
\hline 10 & $\theta$ & + & $+t$ & $t+$ & 100 & 4 & 100 & 2 \\
\hline 11 & $\hat{a}$ & + & $+t$ & ++ & f 400 & 8 & 300 & $\theta$ \\
\hline 12 & $\theta$ & Opal. & + & + & 200 & $\theta$ & 200 & $\theta$ \\
\hline 13 & $\theta$ & Opal. & + & + & 200 & 2 & 200 & $\theta$ \\
\hline 14 & $\theta$ & $\theta$ & + & + & & $\mathrm{f} 4$ & & $\theta$ \\
\hline 15 & $\theta$ & $-t$ & $+t+$ & ++ & 400 & 8 & 300 & 2 \\
\hline 16 & $\theta$ & + & ++ & + & 400 & 2 & 200 & $\theta$ \\
\hline 17 & $\theta$ & $\div$ & $t-t$ & ++ & 400 & 8 & 200 & $\theta$ \\
\hline 18 & $\theta$ & + & ++ & $+t$ & & 4 & & $\theta$ \\
\hline 19 & $\theta$ & $\theta$ & $\operatorname{sech} w+$ & $\operatorname{seh} w+$ & 400 & 4 & 400 & $\theta$ \\
\hline 20 & $\theta$ & $\operatorname{seh} w+$ & $+1-$ & +1 & 400 & 4 & 400 & $\theta$ \\
\hline 21 & $\theta$ & + & $+t$ & $+t$ & & 4 & & $\theta$ \\
\hline 22 & $\theta$ & Opal. & + & + & 400 & 8 & 400 & $\theta$ \\
\hline 23 & $\theta$ & + & $+t$ & + & 300 & 4 & 200 & $\theta$ \\
\hline 24 & $\theta$ & schw. Opal. & $t$ & $\operatorname{seh} w+$ & 300 & 4 & 300 & $\theta$ \\
\hline 25 & $\theta$ & + & $+t$ & ++ & 400 & 8 & 400 & $\theta$ \\
\hline 26 & $\theta$ & Opal. & + & + & 400 & 4 & 400 & $\theta$ \\
\hline 27 & $\theta$ & $\operatorname{sch} w .+$ & $t+$ & ++ & f $\theta$ & $\theta$ & 400 & $\theta$ \\
\hline 28 & $\theta$ & Opal. & + & + & $\theta$ & $2 ?$ & 400 & $\theta$ \\
\hline 29 & $\theta$ & Spur Opal. & + & + & $\theta$ & 8 & 400 & $\theta$ \\
\hline 30 & $\theta$ & Opal. & $+t$ & $t+$ & $\theta$ & $\theta$ & 400 & $\theta$ \\
\hline 31 & $\theta$ & Opal. & + & + & 400 & 8 & 400 & 8 \\
\hline 32 & $\theta$ & Opal. & + & + & 300 & $\theta$ & 400 & $\theta$ \\
\hline 33 & $\theta$ & Opal. & $+t$ & ++ & 300 & 6 & 400 & $\theta$ \\
\hline 34 & $\theta$ & $+t$ & +++ & $+t$ & 200 & 8 & 400 & 8 \\
\hline 35 & $\theta$ & $+t$ & $t+t$ & ++ & 300 & 6 & 100 & $\theta$ \\
\hline 36 & $\theta$ & $\theta$ & Opal. & Opal. & 400 & 4 & 300 & $\theta$ \\
\hline 37 & $\theta$ & Opal. & $t+$ & + & 100 & & 200 & $\theta$ \\
\hline 38 & $\theta$ & + & $+t+$ & $t+t$ & f 400 & 6 & 400 & $\theta$ \\
\hline 39 & $\theta$ & Opal. & ++ & + & 300 & $\theta$ & 300 & $\theta$ \\
\hline 40 & $\theta$ & + & + & Opal. & 200 & 4 & 300 & $\theta$ \\
\hline 41 & $\theta$ & + & $+t+$ & $+t$ & 100 & 8 & 100 & $\theta$ \\
\hline 42 & $\theta$ & $t+t$ & +++ & ++ & & & & $\theta$ \\
\hline 43 & $\theta$ & Opal. & +1 & + & & & & $\theta$ \\
\hline 44 & $\theta$ & Spur Opal. & ++ & + & & & & $\theta$ \\
\hline 45 & $\theta$ & Opal. & $+t$ & $+t$ & 200 & 2 & 200 & $\theta$ \\
\hline 46 & $\theta$ & $++t$ & $t+t$ & +++ & 400 & f 6 & 100 & $\theta$ \\
\hline 47 & $\theta$ & Opal. & + & + & 300 & & 400 & $\theta$ \\
\hline 48 & $\theta$ & + & $+1+$ & +++ & 400 & 6 & 400 & $\theta$ \\
\hline 49 & $\theta$ & $\theta$ & t- & +1 & 100 & 4 & 300 & $\theta$ \\
\hline
\end{tabular}

Z. f. d. ges. Neur. u. Psych. O. XXII. 
(Fortsetzung von Tabelle V.)

\begin{tabular}{|c|c|c|c|c|c|c|c|c|c|c|}
\hline \multirow{2}{*}{ 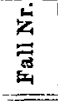 } & \multicolumn{5}{|c|}{ Ammoniumsulfarsättigung } & \multirow[b]{2}{*}{$50 \%$} & \multicolumn{2}{|c|}{$\begin{array}{c}\text { Normal- } \\
\text { amboceptor }\end{array}$} & \multicolumn{2}{|c|}{ Komplement } \\
\hline & $24 \%$ & $28 \%$ & $33 \%$ & $40 \%$ & & & Blut & Liquor & Blut & Liquor \\
\hline 50 & $\theta$ & $\theta$ & $\theta$ & + & & + & 400 & 8 & 400 & $\theta$ \\
\hline 51 & $\theta$ & $\theta$ & $\theta$ & + & & $+t$ & & 4 & & $\theta$ \\
\hline 52 & $\theta$ & $\theta$ & $\theta$ & $+t$ & & ++ & 400 & 8 & 400 & $\theta$ \\
\hline 53 & $\theta$ & $\theta$ & + & +++ & & $++t$ & 300 & 6 & 300 & $\theta$ \\
\hline 54 & $\theta$ & $\theta$ & + & ++ & & ++ & 100 & 2 & 300 & $\theta$ \\
\hline 55 & $\theta$ & $\theta$ & + & +++ & & ++ & 400 & 4 & 300 & $\theta$ \\
\hline 56 & $\theta$ & $\theta$ & Spur Opal. & + & & + & 100 & 2 & 300 & $\theta$ \\
\hline 57 & $\theta$ & $\theta$ & + & $t+t$ & & $++t$ & 200 & 6 & 400 & $\theta$ \\
\hline 58 & $\theta$ & $\theta !$ & Opal. & ++ & & ++ & 300 & 8 & 400 & $\theta$ \\
\hline 59 & $\theta$ & $\theta$ & Opal. & + & & + & 100 & 4 & 300 & $\theta$ \\
\hline 60 & $\theta$ & $\theta$ & Opal. & $++t$ & 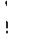 & ++ & & 6 & & $\theta$ \\
\hline 61 & $\theta$ & $\theta$ & Opal. & ++ & & ++ & 400 & 8 & 100 & $\theta$ \\
\hline 62 & $\theta$ & $\theta$ & Opal. & $+t$ & & $+t$ & 100 & 4 & 100 & $\theta$ \\
\hline 63 & $\theta$ & $\theta$ & $\theta$ & + & & ++ & 400 & 8 & 300 & $\theta$ \\
\hline 64 & $\theta$ & $\theta$ & Opal. & $+t$ & & ++ & 400 & 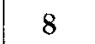 & 400 & $\theta$ \\
\hline 65 & $\theta$ & $\theta$ & $\theta$ & Opal. & & + & 400 & 8 & 300 & $\theta$ \\
\hline 66 & $\theta$ & $\theta$ & Opal. & $t+$ & & $+t$ & 400 & 8 & 100 & $\theta$ \\
\hline 67 & $\theta$ & $\theta$ & $\theta$ & $+t$ & & $+t$ & 400 & 8 & 400 & $\theta$ \\
\hline 68 & $\theta$ & $\theta$ & Opal. & $t+$ & & $++t$ & 100 & 4 & 300 & $\theta$ \\
\hline 69 & $\theta$ & $\theta$ & $\theta$ & + & & $+t$ & 150 & 8 & 100 & $\theta$ \\
\hline 70 & $\theta$ & $\theta$ & schw. + & $+t+$ & & $+t+$ & 200 & 6 & 100 & $\theta$ \\
\hline 71 & $\theta$ & $\theta$ & Opal. & $+t+$ & 1 & $+t+$ & 200 & $\theta$ & 100 & $\theta$ \\
\hline 72 & $\theta$ & $\theta$ & $\theta$ & Opal. & & + & 100 & 2 & $\theta$ & $\theta$ \\
\hline 73 & $\theta$ & $\theta$ & Opal. & $t+$ & & ++ & 300 & 2 & 150 & $\theta$ \\
\hline 74 & $\theta$ & $\theta$ & Spur Opal. & ++ & 1 & $+t$ & 400 & 8 & 400 & $\theta$ \\
\hline 75 & $\theta$ & $\theta$ & Opal. & + & i & + & 150 & $\theta$ & 200 & $\theta$ \\
\hline 76 & $\theta$ & $\theta$ & Opal. & ++ & $\vdots$ & $t+$ & 400 & 6 & 100 & $\theta$ \\
\hline 77 & $\theta$ & $\theta$ & schw. + & $t+t$ & i & $t+t$ & 100 & 4 & 200 & $\theta$ \\
\hline 78 & $\theta$ & $\theta$ & Opal. & ++ & 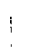 & ++ & 400 & 6 & 400 & $\theta$ \\
\hline 79 & $\theta$ & $\theta$ & Opal. & ++ & & ++ & $\theta$ & 8 & 100 & $\theta$ \\
\hline 80 & $\theta$ & $\theta$ & $\theta$ & + & ! & + & 400 & 6 & 400 & $\theta$ \\
\hline 81 & $\theta$ & $\theta$ & ++ & $++t$ & & $+t+$ & 100 & 4 & 100 & $\theta$ \\
\hline 82 & $\theta$ & $\theta$ & Opal. & $+t$ & & $+t$ & 100 & 6 & 100 & $\theta$ \\
\hline 83 & $\theta$ & $\theta$ & $\theta$ & + & & + & 300 & 8 & 300 & $\theta$ \\
\hline 84 & $\theta$ & $\theta$ & $\theta$ & + & & + & 200 & $\theta$ & 200 & $\theta$ \\
\hline 85 & $\theta$ & $\theta$ & Opal. & ++ & & $+t$ & 400 & f 8 & 400 & $\theta$ \\
\hline 86 & $\theta$ & $\theta$ & Opal. & ++ & & ++ & 200 & 6 & 100 & $\theta$ \\
\hline 87 & $\theta$ & $\theta$ & Spur Opal. & + & 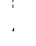 & + & 100 & 8 & $\theta$ & $\theta$ \\
\hline 88 & $\theta$ & $\theta$ & deutl. Opal. & + & 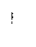 & + & 100 & 4 & 400 & $\theta$ \\
\hline 89 & $\theta$ & $\theta$ & $\theta$ & + & & + & & 0 & & \\
\hline 90 & $\theta$ & $\theta$ & Spur Opa & + & & + & 100 & 2 & $\theta$ & $\theta$ \\
\hline 91 & $\theta$ & $\theta$ & Spur Opal. & + & & + & 400 & 0 & 200 & $\theta$ \\
\hline 92 & $\theta$ & $\theta$ & $\theta$ & Opal. & & + & 100 & $\theta$ & $\theta$ & $\theta$ \\
\hline 93 & $\theta$ & $\theta$ & $\theta$ & deutl. Opal. & & ++ & 300 & $\theta$ & 400 & $\theta$ \\
\hline 94 & $\theta$ & $\theta$ & schw. Opal. & + & & + & 100 & 2 & 100 & $\theta$ \\
\hline 95 & & $\theta$ & $\theta$ & + & & + & 400 & 8 & 400 & $\theta$ \\
\hline 96 & $\theta$ & $\theta$ & schw. Opal. & $\operatorname{sch} w .+$ & & $+t$ & & 8 & & 8 \\
\hline 97 & $\theta$ & $\theta$ & Opal. & ++ & & $+t$ & 100 & 2 & 300 & $\theta$ \\
\hline 98 & $\theta$ & $\theta$ & Opal. & +++ & & $+t+$ & 400 & 2 & 400 & $\theta$ \\
\hline 99 & $\theta$ & $\theta$ & Opal. & + & 1 & + & 100 & 2 & $\theta$ & $\theta$ \\
\hline 100 & $\theta$ & $\theta$ & $\theta$ & Opal. & & + & 300 & 4 & 0 & 0 \\
\hline
\end{tabular}


Tabelle VI.

Beziehungen zwischen den verschiedenen Eiweißreaktionen und dem Normalamboceptor resp. Komplementgehalt.

\begin{tabular}{|c|c|c|c|c|c|c|c|}
\hline \multirow{2}{*}{$\begin{array}{l}\text { Fall } \\
\text { Nr. }\end{array}$} & \multirow{2}{*}{ Pandy } & \multirow{2}{*}{ Nogucbi } & \multirow{2}{*}{$\begin{array}{l}\text { Braun- } \\
\text { Husler }\end{array}$} & \multicolumn{2}{|c|}{ Normalamboceptor } & \multicolumn{2}{|c|}{ Komplement } \\
\hline & & & & Blut & Liquor & Blut & Liquor \\
\hline 1 & $t+$ & + & Opal. & 200 & 2 & f 200 & $\theta$ \\
\hline 2 & $t+t$ & $+t+$ & deutl. Trbg. & - & 8 & - & $\theta$ \\
\hline 3 & ++ & ++ & Opal. & 100 & 8 & 400 & 8 \\
\hline 4 & $+t$ & $t+$ & + & 400 & 8 & 400 & 8 \\
\hline 5 & ++ & + & $\theta$ & 200 & 8 & 300 & $\theta$ \\
\hline 6 & $t+$ & + & leichte Opal. & 400 & 8 & 400 & $\theta$ \\
\hline 7 & $+t$ & + & $\theta$ & 100 & 2 & 100 & $\theta$ \\
\hline 8 & + & + & Opal. & - & 8 & - & 2 \\
\hline 9 & + & + & Opal. & $\theta$ & f 4 & $f \theta$ & $\theta$ \\
\hline 10 & $+t$ & & & 100 & 4 & 100 & 2 \\
\hline 11 & $+t$ & $+t$ & $\theta$ & f 400 & 8 & 300 & $\theta$ \\
\hline 12 & $+t$ & ++ & $\theta$ & 200 & $\theta$ & 200 & $\theta$ \\
\hline 13 & + & + & $\theta$ & 200 & 2 & 200 & $\theta$ \\
\hline 14 & + & + & - & - & f 4 & - & $\theta$ \\
\hline 15 & $+t$ & ++ & Spur Opal. & 400 & 8 & 300 & 2 \\
\hline 16 & $t+$ & $+t$ & Opal. & 400 & 2 & 200 & $\theta$ \\
\hline 17 & $+t$ & + & $\theta$ & 400 & 8 & 200 & $\theta$ \\
\hline 18 & $+t$ & + & + & - & 4 & - & $\theta$ \\
\hline 19 & $\theta$ & $\theta$ & $\theta$ & 400 & 4 & 400 & 4 \\
\hline 20 & ++ & $+t$ & schw. Opal. & 400 & 4 & 400 & $\theta$ \\
\hline 21 & ++ & $+t$ & $\theta$ & - & 4 & - & $\theta$ \\
\hline 22 & ++ & $+t$ & schw. Opal. & 400 & 8 & 400 & $\theta$ \\
\hline 23 & $+t$ & $+t$ & schw. + & 300 & 4 & 200 & $\theta$ \\
\hline 24 & + & + & deutl. Opal. & 300 & 4 & 300 & $\theta$ \\
\hline 25 & ++ & $+t$ & - & 400 & 8 & 400 & $\theta$ \\
\hline 26 & + & + & - & 400 & 4 & 400 & $\theta$ \\
\hline 27 & $+t$ & + & + & f $\theta$ & $\theta$ & 400 & $\theta$ \\
\hline 28 & + & schw. + & Opal. & $\theta$ & $2 ?$ & 400 & $\theta$ \\
\hline 29 & + & + & Trübung & $\theta$ & 8 & 400 & $\theta$ \\
\hline 30 & $+t$ & + & $\theta$ & $\theta$ & $\theta$ & 400 & $\theta$ \\
\hline 31 & + & + & $\theta$ & 400 & 8 & 400 & 8 \\
\hline 32 & $t+$ & $+t$ & $\theta$ & 300 & $\theta$ & 400 & $\theta$ \\
\hline 33 & $+t$ & + & $\theta$ & 300 & 6 & 400 & $\theta$ \\
\hline 34 & $++t$ & $+t$ & $\theta$ & 200 & 8 & 400 & 8 \\
\hline 35 & $+t$ & $+t+$ & schw, Opal. & 300 & 6 & 100 & $\theta$ \\
\hline 36 & $\operatorname{sch} w .+$ & $\theta$ & $\theta$ & 400 & 4 & 300 & $\theta$ \\
\hline 37 & + & + & $\theta$ & 100 & 一 & 200 & - \\
\hline 38 & $t+$ & $t+$ & $\theta$ & f 400 & 6 & 400 & $\theta$ \\
\hline 39 & + & + & $\theta$ & 300 & $\theta$ & 300 & $\theta$ \\
\hline 40 & + & + & $\theta$ & 200 & 4 & 300 & $\theta$ \\
\hline 41 & $++t$ & +++ & $\theta$ & 100 & 8 & 100 & $\theta$ \\
\hline 42 & $t+$ & $+t+$ & - & - & 一 & - & - \\
\hline 43 & $+t$ & $t+t$ & $\theta$ & - & - & - & - \\
\hline 44 & $+t$ & $+t$ & - & $\ldots$ & 一 & - & - \\
\hline 45 & $+t$ & + & $\theta$ & 200 & 2 & 200 & $\theta$ \\
\hline 46 & $+t$ & $+t$ & deutl. Opal. & 400 & $\mathrm{f} \theta$ & 100 & $\theta$ \\
\hline 47 & $+t$ & $\operatorname{seh} w .+$ & - & 300 & - & 400 & $\theta$ \\
\hline 48 & $+t$ & $t+$ & Opal. & 400 & 6 & 400 & $\theta$ \\
\hline 49 & $t+$ & + & $\theta$ & 100 & 4 & 300 & $\theta$ \\
\hline
\end{tabular}


(Fortsetzung von Tabelle VI.)

\begin{tabular}{|c|c|c|c|c|c|c|c|}
\hline \multirow{2}{*}{$\begin{array}{l}\text { l'all } \\
\text { Nr. }\end{array}$} & \multirow{2}{*}{ Pandy } & \multirow{2}{*}{ Noguchi } & \multirow{2}{*}{$\begin{array}{l}\text { Braun- } \\
\text { Husler }\end{array}$} & \multicolumn{2}{|c|}{ Normalamboceptor } & \multicolumn{2}{|c|}{ Komplement } \\
\hline & & & & Blut & Liquor & Blut & Laquor \\
\hline 50 & $+t$ & + & $\theta$ & 400 & 8 & 400 & 0 \\
\hline 51 & ++ & $\div$ & schw. Opal. & $\cdots$ & 4 & 一 & - \\
\hline 52 & $+t+$ & $+i t$ & Opal. & 400 & 8 & 400 & $\theta$ \\
\hline 53 & $+t+$ & $++-1-$ & deutl. Opal. & 300 & 6 & 300 & 0 \\
\hline 54 & $+t+$ & $++-1-$ & Opal. & 100 & 2 & 300 & 0 \\
\hline 55 & $+t+$ & $++t$ & Opal. & 400 & 4 & 300 & 0 \\
\hline 56 & $+t+$ & $+t$ & Spur Opal. & 100 & 2 & 300 & 0 \\
\hline 57 & $+t-t$ & $++t$ & - & 200 & 6 & 400 & $\theta$ \\
\hline 58 & $+t+$ & $+t+$ & Opal. & 300 & 8 & 400 & 0 \\
\hline 59 & +++ & $+t$ & deutl. Opal. & 100 & 4 & 300 & $\theta$ \\
\hline 60 & $+t+$ & $t+t$ & leichte Opal. & - & 6 & - & () \\
\hline 61 & $+t+$ & $t-t+$ & Opal. & 400 & 8 & 100 & 0 \\
\hline 62 & ++ & $+t+$ & Opal. & 100 & 4 & 100 & $\theta$ \\
\hline 63 & ++ & $+t$ & deutl. + & 400 & 8 & 300 & $\theta$ \\
\hline 64 & $+-t$ & +1 & Opal. & 400 & 8 & 400 & $\theta$ \\
\hline 65 & + & $t+$ & schw. Opal. & 400 & 8 & 300 & $\theta$ \\
\hline 66 & $++t$ & ++ & Opal. & 400 & 8 & 100 & $\theta$ \\
\hline 67 & $+\div+$ & $+t$ & $\theta$ & 400 & 8 & 400 & $\theta$ \\
\hline 68 & $++t$ & +++ & Opal. & 100 & 4 & 300 & $\theta$ \\
\hline 69 & +++ & ++ & Opal. & 150 & 8 & 100 & $\theta$ \\
\hline 70 & $t+t$ & $+t+$ & schw. Opal. & 200 & 6 & 100 & $\theta$ \\
\hline 71 & $++t$ & $t+t$ & Opal. & 200 & 0 & 100 & $\theta$ \\
\hline 72 & $+t$ & + & Opal. & 100 & 2 & $\theta$ & $\theta$ \\
\hline 73 & $t+t$ & ++-1 & Opal. & 300 & 2 & 150 & 0 \\
\hline 74 & +++ & $+1+$ & Opal. & 400 & 8 & 400 & $\theta$ \\
\hline 75 & $-+\cdot+$ & + & Opal. & 150 & $\theta$ & 200 & $\theta$ \\
\hline 76 & $+t+$ & $+t+$ & Opal. & 400 & 6 & 100 & 0 \\
\hline 77 & $+t+$ & ++- & Opal. & 100 & 4 & 200 & $\theta$ \\
\hline 78 & $+t+$ & $+t+$ & Opal. & 400 & 6 & 400 & 0 \\
\hline 79 & $+t+$ & $t-++t$ & Opal. & $\theta$ & 8 & 100 & $\theta$ \\
\hline 80 & -- & - & - & 400 & 6 & 400 & $\theta$ \\
\hline 81 & +++ & $+t+$ & deutl. Opal. & 100 & 4 & 100 & 0 \\
\hline 82 & $++t$ & $t+$ & Opal. & 100 & 6 & 100 & $\theta$ \\
\hline 83 & $+t$ & - & Opal. & 300 & 8 & 300 & $\theta$ \\
\hline 84 & $t+$ & ++ & Opal. & 200 & $\theta$ & 200 & $\theta$ \\
\hline 85 & +++ & $+t+$ & Opal. & 400 & f 8 & 400 & $\theta$ \\
\hline 86 & ++ & + & Opal. & 200 & 6 & 100 & $\theta$ \\
\hline 87 & + & + & $\theta$ & 100 & 8 & $\theta$ & $\theta$ \\
\hline 88 & $t+$ & ++ & Spur Opal. & 100 & 4 & 400 & $\theta$ \\
\hline 89 & ++ & + & schw. Opal. & - & $\theta$ & - & 一 \\
\hline 90 & $+t$ & $+t$ & Spur Opal. & 100 & 2 & $\theta$ & $\theta$ \\
\hline 91 & $+t+$ & $+t$ & Spur Opal. & 400 & $\theta$ & 100 & $\theta$ \\
\hline 92 & + & schw. + & $\theta$ & 100 & $\theta$ & $\theta$ & $\theta$ \\
\hline 93 & $+t$ & ++ & Opal. & 300 & $\theta$ & 400 & 0 \\
\hline 94 & + & + & $\theta$ & 100 & 2 & 100 & $\theta$ \\
\hline 95 & + & $\operatorname{sch} w .+$ & - & 400 & 8 & 400 & 0 \\
\hline 96 & $+t+$ & $+t+$ & Opal. & - & 8 & - & 8 \\
\hline 97 & ++ & + & Opal. & 100 & 2 & 300 & $\theta$ \\
\hline 98 & $t+t$ & $++t$ & Opal. & 400 & 2 & 400 & $\theta$ \\
\hline 99 & + & + & Opal. & 100 & 2 & $\theta$ & $\theta$ \\
\hline 100 & + & $\operatorname{seh} w .+$ & $\theta$ & 300 & 4 & $\theta$ & $\theta$ \\
\hline
\end{tabular}


50 proz. Sättigung mit Ammoniumsulfat, die Phase I läßt ka um noch einen solchen erkennen.

Der Komplementübergang scheint zu der Pseudoglobulinfraktion in größerer Bexiehung zu stehen, indem in 3 der Fälle $(8,15$, 34) eine +++ starke Reaktion der Komplementstärke von $1 / 150,1 / 50$ (in Fall 8?) entspricht, während jene von $1 / 50$ in Fall 3 und 10 mit einer $+t$, jene von $1 / 50$ in Fall mit einer + , jene in Fall 96 mit einer schwach positiven Pseudoglobulinreaktion einhergeht. Die Euglobulinreaktion ist nur in Fall 34 stärker, sonst immer + oder Opalescenz; nie ging rler Komplementgehalt mit riner Ausfällung bei $28 \%$ Ammoniumsulfatsïttigung einher.

ther vergleichende Bostimmungen der verschiedenen Ammoniumsulfatfraktionen wird später zu berichten sein.

Cher die Bezieh ungen zwisehen don verschiedenon Eiweißreationan und dem Normalamboceptor und Komplementgehalt dar Śpinalflüssigkeit klärt ums Tabelle VI auf. Betrachten wir vor allem die Braun-Huslersche Reaktion, so entspricht ihrem negativen Ausfall in Fall 5 einc Amboceptorstärke von 1/2.5, in Fall 7 von 1/50, in Fall 13 von $1 / 100$. in Fall 34 wieder von $1 / 25$, in Fall 39 von $\theta$. Einer stärkeren Reaktion steht in Fall 3 die Amboceptorstärke von 1/,0 gegenüber, ebenso in Fall 63, während in Fall 23 der Amboceptorübergang sieh mit 1/5, darstellen läl3t. Die meist vorhandene Stärke: Opalescenz, geht, wie ersichtlich, mit verschiedenen Amboceptorüber. gängen Hand in Hand. Viel besser ist das Resultat auch neiht, wenn wir die Nogruchische oder Pandysche Reaktion mit den für Normalamboceptordurchtritt erhaltenen Zahlen vergleichen. Für Noguchi: die negativen Reaktionen in Fall 19 und 36 bestehen bei doch vorhandener Amboceptorenstïrke von 1/100, dic + Reaktionen können mit 1/100 (Fall 26), 1/50 (Fall 17), 1/25 (Fall 5) Amboceptorzahlen auftreten, während der ganz starken Reaktion $(+++)$ in Fall $981 / 200$, in Fall 55 $1 / 100$, in mehreren Fällen $1 / 2.5$ gegenübersteht. (kanz ähnlich verhält es sich mit der Pandyschen Reaktion.

Um nun dem Vorwurf zu begegnen, wir hätten zur Stütze der Behauptung, daß die Beziehung zwischen den verschiedenen Reaktionen und dem Normalamboceptor - resp. Komplementübertritt nur bestimmte Fälle der Tabelle entnommen, nicht aber mit der Menge der Fälle selbst gerechnet, haben wir folgende Tabellen VII und VIII zusammengestellt, a us denen sich ergibt, mit wieviel Fällen von verschiedenen Stärken des Amboceptorübertrittes bestimmte Intensitäten der Reaktionen Hand in Hand gehen. Für den Komplementübertritt ist eine solche Zusammenstellung wegen der geringen Anzahl der Fälle wohl nicht nötig. Aus 'Tabelle VII und VIII ergibt sich nun nochmals mit voller Deutlichkeit die Wahrheit unserer Schlüsss, indem bei irgendwelchen Beziehungen 
Tabelle VII.

Zusammenfassung der Beziehungen zwischen Globulinfraktion und Normalamboceptorubergang.

\begin{tabular}{|c|c|c|c|c|c|c|c|c|c|c|c|c|c|c|c|c|c|c|}
\hline \multirow{2}{*}{ Reaktion } & \multirow{2}{*}{ Stärke } & \multirow{2}{*}{ Fălle } & \multicolumn{16}{|c|}{ Normalamboceptorïbergang } \\
\hline & & & $\theta$ & $1,200 \mid$ & $1 / 150$ & $1 / 100 \mid$ & $\begin{array}{l}1 \\
1 ; 86\end{array}$ & $1 / 86$ & $1 / 80$ & $1 / 97$ & $1 / s s$ & $1 / 23$ & $|1 / 20|$ & $1 / 18$ & $1 / 12$ & 2 & 4 & 8 \\
\hline $\begin{array}{c}\mathbf{3 3} \text { proz. } \\
\text { Ammonium- } \\
\text { sulfat- } \\
\text { sättigung }\end{array}$ & $\begin{array}{c}\theta \\
\text { Opal. } \\
\text { schw. und }+ \\
++ \\
+++\end{array}$ & $\begin{array}{r}11 \\
40 \\
23 \\
3 \\
1\end{array}$ & $\begin{array}{l}1 \\
6\end{array}$ & 1 & 1 & $\begin{array}{l}1 \\
5 \\
2\end{array}$ & $\begin{array}{l}1 \\
1 \\
2\end{array}$ & $\begin{array}{l}1 \\
2 \\
2\end{array}$ & $\begin{array}{r}4 \\
13 \\
9 \\
2\end{array} \mid$ & $\begin{array}{l}1 \\
1\end{array}$ & $\begin{array}{l}1 \\
2\end{array}$ & $\begin{array}{l}1 \\
3 \\
3 \\
1\end{array}$ & $\mathbf{I}$ & 1 & & 1 & 1 & 2 \\
\hline $\begin{array}{l}40 \text { proz. } \\
\text { Ammonium- } \\
\text { sulfat- } \\
\text { sättigung }\end{array}$ & $\begin{array}{c}\theta \\
\text { Opal. } \\
\text { schw. }+ \text { und }+ \\
++ \\
+++\end{array}$ & $\begin{array}{r}\theta \\
6 \\
27 \\
31 \\
13\end{array}$ & $\begin{array}{l}2 \\
3 \\
1 \\
1\end{array}$ & 1 & 2 & $\begin{array}{l}1 \\
3 \\
3 \\
1\end{array}$ & $\begin{array}{l}1 \\
3 \\
1\end{array}$ & $\begin{array}{l}1 \\
2 \\
3 \\
\end{array}$ & $\left|\begin{array}{r}2 \\
9 \\
13 \\
4\end{array}\right|$ & $\begin{array}{l}1 \\
1\end{array}$ & 2 & $\begin{array}{l}2 \\
3 \\
2 \\
\end{array}$ & 1 & $\begin{array}{l}1 \\
1\end{array}$ & $\begin{array}{l}1 \\
1\end{array}$ & 1 & 1 & $\begin{array}{l}1 \\
1\end{array}$ \\
\hline $\begin{array}{c}50 \text { proz. } \\
\text { Ammonium- } \\
\text { sulfat- } \\
\text { sättigung }\end{array}$ & $\begin{array}{c}\theta \\
\text { Opal. } \\
\text { schw. }+ \text { und }+ \\
++ \\
+++\end{array}$ & $\begin{array}{r}\theta \\
2 \\
31 \\
26 \\
13\end{array}$ & 7 & $\begin{array}{l}1 \\
1\end{array}$ & $\begin{array}{l}1 \\
1\end{array}$ & \begin{tabular}{l|l}
1 & \\
2 & \\
1 & \\
1 &
\end{tabular} & 2 & $\begin{array}{l}2 \\
3 \\
3\end{array}$ & $\begin{array}{r}1 \\
14 \\
16 \\
1\end{array}$ & $\begin{array}{l}1 \\
1\end{array}$ & $\begin{array}{l}1 \\
2\end{array}$ & $\begin{array}{l}2 \\
1 \\
3\end{array}$ & & 1 & & i 1 & & \\
\hline
\end{tabular}

Tabelle VIII.

Zusammenfassung der Beziehungen zwischen verschiedenen Reaktionen und Normalamboceptorübergang.

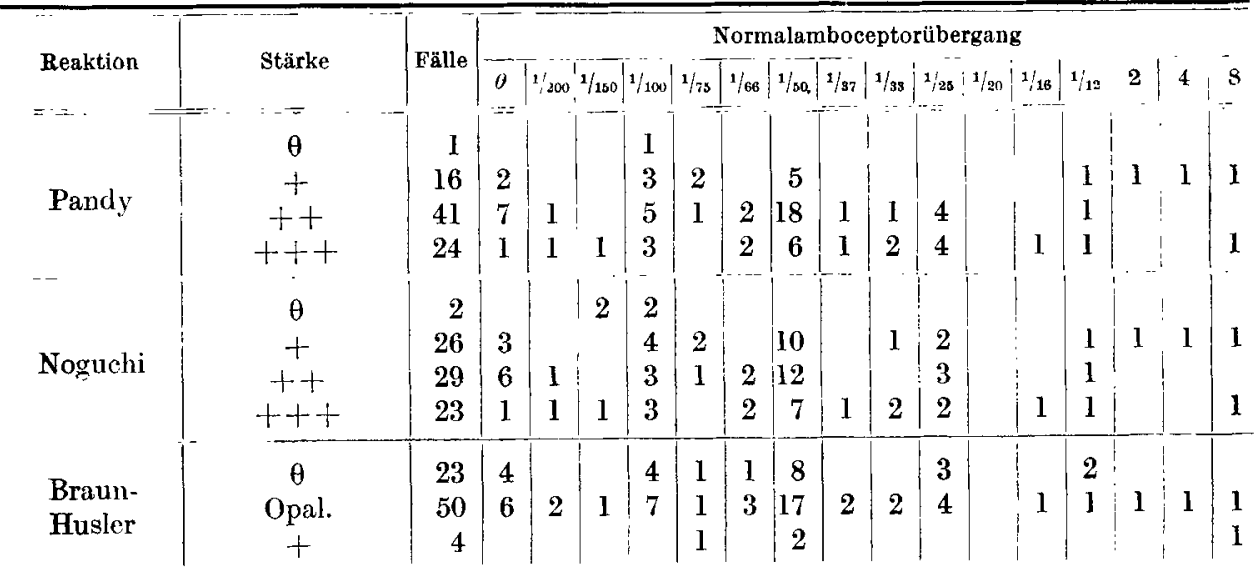

direkter Proportionalität zwischen Stärke der Eiweißreaktion und Normalamboceptorübertritt, sich bei steigender Intensität der Reaktionen die Zahlen nach rechts verschieben müßten, was nicht der Fall ist.

Am Schlusse werden diese Verhältnisse noch näher zu besprechen sein, wo auch von eventuellen praktischen Folgerungen aus obigem die Rede sein wird. 
Wie schon erwähnt, wurde in einer Reihe von Fällen die steige nde Ammoniumsulfatsättigung bei gleichen Liquormengen vorgenommen. Hierüber wird weiter unten zu berichten sein.

Bezüglich der Wassermannschen Reaktion ließen sich ebenfalls keine engeren Beziehungen stiften: 91 Fälle waren bei 0,2 in der Spinalflüssigkeit glatt positiv, trotzdem war der Amboceptorübertritt ein sehr verschiedener und fehlte auch; andererseits konnten wir in Fällen, bei denen die Wassermannsche Reaktion erst bei 0,5 in der Spinalflüssigkeit positiv wurde, einen Ubertritt von $1 / 100,1 / 75,1 / 50$ konstatieren.

\section{II.}

In die Gruppe der fraglichen Paralysen zählten wir die folgenden Fälle, deren Krankengeschichten kurz skizziert seien.

a) Ka. 1909 ins Krankenhaus aufgenommen wegen Schwindelanfällen, Urinretention, Abnahme des Gedächtnisses, Sprachstörung. Es wurde die Diagnose Paralyse gestellt. Die vier Reaktionen waren damals positiv. Seit Juli 1909 in Friedrichsberg. Hier war zu konstatieren: stumpfe Euphorie, Verwirrtheit, Größen ideen, Pupillenstörungen, Sprachstörung, paralytische Schrift, Reflexsteigerung, Ataxie, Hypalgesie. Während das Krankheitsbild bisher stationär blieb, nahmen die Liquor- und Blutreaktionen allmählich ab und zeigen heute den Befund (Tabelle IX, Nr. 102). Im Blute ist nur mit steigenden Konzentrationen eine positive Wasser ma n n sche Reaktion zu erhalten, im Liquor fällt nur — bei nicht erhöhtem Gesamteiweißgehalt - die schwach positive Pandy - Reaktion auf.

b) Ma. wurde 14. 4. 1906 mit der Diagnose progressive Paralyse in Friedrichsberg eingeliefert. Anamnese ungenau. 1905 Sommer sei die Sprache „,häufig“ weggeblieben, (irößenideen, Vergeßlichkeit aufgetreten. Frau: mehrere Aborte. Luische Infektion des Mannes 1878. Paralytischer Aufnahmebefund; stumpf,euphorisch, verwirrt, Größenideen. Im .Juli 1906 trat ein Schlaganfall mit linksseitiger Lähmung auf, dessen Folgen allmählich zurïcktraten. Später schien P, zu halluzinieren und war oft erregt, hatte Schwindelanfälle. Seit 1908 stationäres Bild: erheblich verblödet, apathisch. Dabei Pupillendifferenz, träge Lichtreaktion der Pupillen, Romberg + , Patellarsehnenreflex r. $>1$., Patellarklonus, Sprachstörung. Im Blut (Tab. IX, Nr. 105) stellten sich die positive Sternsche Reaktion und der inkomplet positive Befind nach Normalamboceptorabsorption die Residuen des serologischen Verhaltenis dar; im Liquor wiesen wieder Pandy und Phase I dio einzigen pathologischen Werte auf.

c) Fi. cin Abort, zwci Kinder klcin gestorben. Starke Trinkerin. Wegen Krämpfen Juni 1913 ins Krankenhaus; von dort nach Friedrichsberg wegen Verblödung, Desorientiertheit, Urinretention. Der Aufnahmebefund zeigte Pupillendifferenz, Npur Lichtreaktion, Facialisdifferenz, Steigerung der Sehnenreflexe. Spasmen des Beins, Romberg +, Sprache und Schrift paralytisch, hochgradige Demenz. Inzwischen lcicht gebessert. Die Blut- und Liquorbefunde (Tab. IX, Nr. 106) zeigten: schwach positive Wa sser ma n nsche Reaktion in Blut und Liquor, Komplementschwund im Blute, im Liquor: Phase I opalescent, Pandy: †.

d) Wa. 23. 8. 1902 Kopftrauma, seither Schwindelanfälle, Gedächtnisschwäche, Reizbarkeit, Unfähigkeit zu geistiger Arbeit, Schwerhörigkeit. 1903 wurde Pupillendifferenz und träge Pupillenreaktion konstatiert, ferner Erhöhung des Patellarsehnenreflex, Romberg + . Später wurden die Pupillen lichtstarr, Silbenstolpern und Anfälle von Bewußstosigkeit traten auf. 1906 lanzinierende Schmerzen. In 
Friedrichsberg wurde psychisch und somatisch der Befund der Tabesparalyse erhoben. Die Resultate der Untersuchung der Rückenmarksflüssigkeit und des Blutes (Tab. IX, Nr. 107) zeigen mittlere positive Werte. Im Blute fehlte das Korplement. Der Normalamboceptorübergang in den Liquor ist $1 / 50$, bei schwach positiver Phase I.

e) Ho. Schon 1895 aus seiner Stellung ausgeschieden, weil nicht mehr mitgekommen. Früher ziemlich Potus. Soll nach einer unsicheren Angabe früher auch epileptische Anfälle gehabt haben. $1896 \mathrm{kam}$ er ins Werk- und Armenhaus. Von dort wegen Halluzinationen und Verfolgungsideen I899 nach Friedrichsberg. Hier konstatierte man Pupillendifferenz, Lichtstarre der I. Pupille, Facialisdifferenz, Steigerung der sehnenreflexe; dabei bestanden Sinnestäuschungen und zeitweise Erregungszustände. Später (1903) wurde auch herabgesetzte Lichtreaktion der r. Pupille konstatiert. Bei fortschreitender Demenz hielt er an scinen früheren Wahnideen fest, Sprachstörung. 1912 wurde Pleocytose, positive Phase I, positive Wassermannsche Reaktion in Blut und Liquor konstatiert. Später immer gleichbleibendes Zustandsbild: Demenz mit etwas Euphorie, zeitweise anscheinend auch Halluzinationen. Nach einer Lumbalpunktion ein Jacksonscher Anfall, der einem paralytischen sehr ähnlich war. Die Liquorreaktionen wurden allmählich schwächer, um (Tab. IX, Nr. 112) in der letzten Zeit $\left({ }^{19} / 7\right)$ das hier aufgezeichnete Bild zu geben.

Tabelle IX

\begin{tabular}{|c|c|c|c|c|c|c|c|c|c|c|c|}
\hline \multirow{3}{*}{$\begin{array}{l}\text { Fall } \\
\text { Yr. }\end{array}$} & \multirow{3}{*}{ Datum } & \multicolumn{7}{|c|}{ Liquor } & \multirow{3}{*}{ 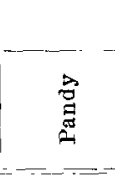 } & \multirow{3}{*}{ 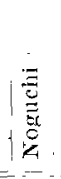 } & \multirow{3}{*}{ 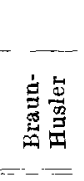 } \\
\hline & & \multirow{2}{*}{\multicolumn{2}{|c|}{ : }} & & \multirow[b]{2}{*}{\begin{tabular}{|l|l|}
4 \\
6 \\
\end{tabular}} & \multicolumn{3}{|c|}{ Globulinfraktion } & & & \\
\hline & & & & & & $\begin{array}{l}33 \\
\% \\
\end{array}$ & $\begin{array}{l}40 \\
\% \\
\end{array}$ & $\begin{array}{l}50 \\
\% \\
\end{array}$ & & & \\
\hline $102 \mathrm{a}$ & 29. 7. 1913 & & $2 / 3$ & $\theta$ & $\theta$ & $\theta$ & $\theta$ & sehw. Opal. & schw. $t$ & -10 & $\theta$ \\
\hline $105 \mathrm{~b}$ & 3. 7.1913 & & $6 / 3$ & $\theta$ & $\theta$ & $\theta$ & Opal. & Opal. & + & $\theta$ & $\theta$ \\
\hline $106 \mathrm{c}$ & 28. 6. 1913 & & $1 / 3$ & $\theta$ & & $\theta$ & $\theta$ & Opal. & $-t^{-}$ & + & $\theta$ \\
\hline $107 d$ & 9. 7.1913 & & 51 & $\theta$ & & $\theta$ & Spur Opal. & schw. + & ++ & +1 & \\
\hline $112 \mathrm{e}$ & 29. 7.1913 & & $2 / 3$ & $\theta$ & $\theta$ & $\theta$ & Opal. & + & + & +1 & $\theta$ \\
\hline $115 \mathrm{f}$ & 31. 7.1913 & gelb & 105 & $\theta$ & $\theta$ & Opal. & $+t+$ & $++t$ & ++ & -+1 & schw: \\
\hline & 23. 9. 1913 & $\begin{array}{c}\text { nach dem } \\
\text { Anfall }\end{array}$ & $16 / 3$ & $\theta$ & $\theta$ & $\theta$ & Opal. & schw. + & $+\div$ & $|-\ldots|$ & $\begin{array}{l}\text { Opal. } \\
\text { scliw. }\end{array}$ \\
\hline $118 \mathrm{~g}$ & 27. 9.1913 & & $6 / 3$ & $\theta \mid$ & $\theta$ & $\theta$ & $\theta$ & $\theta$ & $\theta$ & $\theta$ & $\theta$ \\
\hline $134 \mathrm{~h}$ & 3. 7.1913 & & $6 / 3$ & $\theta$ & & $\theta$ & $\theta$ & Opal. & $\theta$ & $\theta$ & $\theta$ \\
\hline $151 \mathrm{i}$ & 6. 8.1913 & senwarz & $6 / 3$ & $\theta$ & $\theta$ & $\theta$ & $\theta$ & $\theta$ & $\theta$ & $\theta$ & $\theta$ \\
\hline
\end{tabular}

f) Sche., geb. 1860, erlitt 1903 einen Schlaganfall. 1909 trat wieder ein Anfall auf mit folgender Sprachstörung, ferner Schwindelanfälle, Abnahme des Gedächt. nisses. Luetische Infektion 1894. War August 1911 im Krankenkaus wegen Lues cerebri in Behandlung, damals Pupillen: r. träge ragierend, l. Lichtstarre. Differenz der Patellarsehenreflexe, Romberg + . Liquor xanthochrom, alle Reaktionen stark positiv. War dann mehrmals mit wechselnden Befunden im Krankenhaus. April 1913 wurde er wieder ins Krankenhaus aufgenommen: Lichtstarre Pupillen, Fußklonus, gesteigerte Reflexe. Juli 1913 wieder aufgenommen wegen Krämpfen und Kopfverletzung. Es bestanden auch heftige Erregungszustände, weshalb er nach Friedrichsberg verlegt wurde. Hier wurde (28. 7. 1913) folgendes statuiert: Pupillendifferenz, beide lichtstarr, Facialisdifferenz, Steigerung der Reflexe, Romberg +. Ataxie, artikulatorische Sprachstörung; psychisch: Demenz, Merkfähig- 
keitsstörung, zeitweise verwirt und unruhig. Liquor xanthochrom Reaktion s. Tab. IX, Nr. 115. Es wurde dann Schmierkur angefangen, während welcher ein epileptischer Anfall auftrat. Später leichte Besserung, demente Euphorie. Nach einem emeuten epileptiformen Anfall am 23. 9. klarer Liquor. Weiterbestehende euphorische Demenz. Die Blut-und Liquorbefunde sind von Interesse. Am 31. 7. ist der Blutbefund bei $0,2+$, bei $0,5++$, die Ster $n$ - Reaktion ist negativ wegen des im Blut im Überschusse vorhandenen Eigenkomplements. Finer von uns (Kafka) hat iiber dieses Phänomen schon berichtet und es Hyperalexie genamnt. Am 23. 9. war der Blutbefund schwächer, Hyperalexie bestand noch. Dic Wassermannsche Reaktion des Liquors ist am 23. 9. etwas schwächer als am 31. 7. Die: meisten Unterseliede zeigen sich in den Ausfüllungen mit Ammoniumsulfat, wäh. rend am 31. 7. schon bei 33 proz. Nättigung Opaleseenz auftrat, die bei $40 \%$ schon sehr stark war, konnte am 23. 9. erst bei 40 proz. Sättigung Opalescenz konstatiert werden und war Phase I nur schwach + . Pandy, Nog uchi und Braun - Hus ler blieben einander gleich, ebenso der Gesamteiweißgehalt. Beidemal waren Normalamboceptoren im Liquor nachzuweisen, nie Komplement.

g) Ru. Wurde am 2. 9. 1910 wegen Paralyse in Friedrichsberg eingewiesen. Er war gewalttätig gewesen und hätte Größenideen geäußert. Bei der Aufnahmo paralytischer Befund, verwirrt, dement, Größenideen. Luische Infektion zugegeben. Im weiteren Verlaufe stumpf, interesselos. Somatisch unverändert.

Fragliche Paralysen.

\begin{tabular}{|c|c|c|c|c|c|c|c|c|c|c|c|c|c|}
\hline \multirow[b]{2}{*}{ 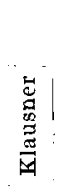 } & \multirow[b]{2}{*}{$\begin{array}{l}\overline{0} \\
\overline{0} \\
\vec{z}\end{array}$} & \multicolumn{2}{|c|}{$\begin{array}{l}\text { Normal- } \\
\text { amboc. }\end{array}$} & \multicolumn{2}{|c|}{$\begin{array}{c}\text { Komple- } \\
\text { ment }\end{array}$} & \multicolumn{6}{|c|}{ Wassermann-Reaktion im Blut } & \multicolumn{2}{|c|}{ WaR. im Lituor } \\
\hline & & 岂 & $\stackrel{\stackrel{5}{g}}{\stackrel{g}{g}}$ & $\stackrel{\Xi}{\oplus}$ & 岂 & 宫悹 & 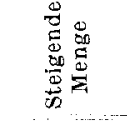 & $\frac{\overrightarrow{0}}{\vec{d}}$ & 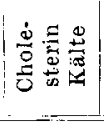 & 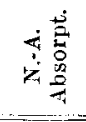 & 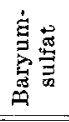 & 㻤咅 & \\
\hline$\theta$ & 0,0135 & 400 & $\theta$ & 300 & $\theta$ & $\theta$ & $0,5 \ldots$ & $\theta$ & & & & $\theta$ & $\theta$ \\
\hline$\theta$ & 0,018 & $300^{\prime}$ & $\theta$ & 300 & 0 & $\theta$ & b. $0,5 \theta$ & $\dot{+}$ & $\theta$ & Spur. & $\theta$ & $\theta$ & b. 1.00 \\
\hline$\theta$ & 0,009 & 400 & $\theta$ & 0 & $\theta$ & $\theta$ & b. $0,5+$ & Selbsth. & $+\frac{1}{1}+$ & & & $\theta$ & $0,5 \mathrm{k}$ \\
\hline & 0,036 & 400 & f 8 & $\theta$ & $\theta$ & ++1 & & Sh. & +++ & & & 0 & $0 . \tilde{5}+++$ \\
\hline & 0,009 & 400 & $\theta$ & 400 & 0 & $++i$ & & $++t$ & $1++1$ & & & $\theta$ & b. $1,0 \theta$ \\
\hline- & $0,0 \tilde{4}$ & 300 & 4 & 500 & $\theta$ & + & b. $0, \bar{s}$ & $\underset{\leftarrow}{\theta}$ & & & & $+4-+$ & \\
\hline- & 0,054 & 100 & 4 & 500 & $\theta$ & $\mathrm{k}$ & b. $0,5-1$ & $\stackrel{\theta}{\leftrightarrow}$ & 0 & & & ++ & b. $0,5+++$ \\
\hline & 0,027 & 200 & $\theta$ & 200 & $\theta$ & $\theta$ & b. $1,0 \theta$ & $\theta$ & $\theta$ & & & $\theta$ & b. $I, 0 \theta$ \\
\hline$\theta$ & 0,0135 & & $\theta$ & & $\theta$ & & & & & & & $\theta$ & b. 0,50 \\
\hline$\longrightarrow$ & 0,0135 & 400 & $\theta$ & 400 & $\theta$ & $\theta$ & b. $1,0 \theta$ & $\theta$ & $\theta$ & & & $\theta$ & b. $1,0 \theta$ \\
\hline
\end{tabular}

Blut- und Liquorbefund ganz negativ, nur Gesamteiweißgehalt vermehrt. (S. Tab. IX, Nr, 118.)

h) Pie. Hier handelte es sich um eine klinisch offenkundige Paralyse, deren Reaktionen in einem anderen Krankenhause untersucht, positiv waren. Nach einer Salvarsankur zeigte sie die in Tab. IX, Nr. 134, angeführten Befunde, bei leichter klinischer Besserung. Sie ist jetzt auf Wunsch des Mannes entlassen.

i) St. 13. 5. 1913. Wegen chronischen Potus mit Verfolgungsideen nach Friedrichsberg verlegt. Aufnahmebefund: Pupillen entrundet, r. $>1$, träge und wenig ausgiebige Lichtreaktion, Facialisdifferenz, Steigerung der Reflexe, Händezittern Sprachstörung.

Anfänglich erregt und Sinnestäuschungen, spätcr ruhiger, dann wieder verwirrt, zeitweise erregt. 
Befunde des Blutes im Liquor (Tabelle IX, Nr. 151] nach allen Richtungen negativ.

Die hier kurz skizzierten Fälle haben an sich manches Interessante, sie werden aber - was gleich vorausgeschickt sein mag - für unsere Fragestellungen weniger verwertbar sein, da sich kaum in einem der Fälle eine ganz sichere Diagnose stellen läßt. Diese Fälle können erst dann vollkommen ausgeschöpft werden, wenn die Anatomie ihr letztes Wort gesprochen hat. Fall a gilt klinisch als Paralyse; er hat das Auffallende, daß das vorgeschrittene Krankheitsbild stationär bleibt und die Reaktionen negativ werden. Fall b wird ebenfalls klinisch als Paralyse angesehen; auch er zeigt ein stationäres, klinisches Verhalten bei negativen oder fast negativen Liquor- und Blutreaktionen. Auch Fall c und $\mathrm{d}$ werden klinisch als Paralysen angesehen, letzterer als etwas atypisch verlaufende Tabesparalyse. Uber Fall e sind die Akten noch lange nicht geschlossen; auch er imponiert als atypische Paralyse, auch er zeigt das Merkwürdige, daß die verschiedenen Reaktionen allmählich

Tabelle

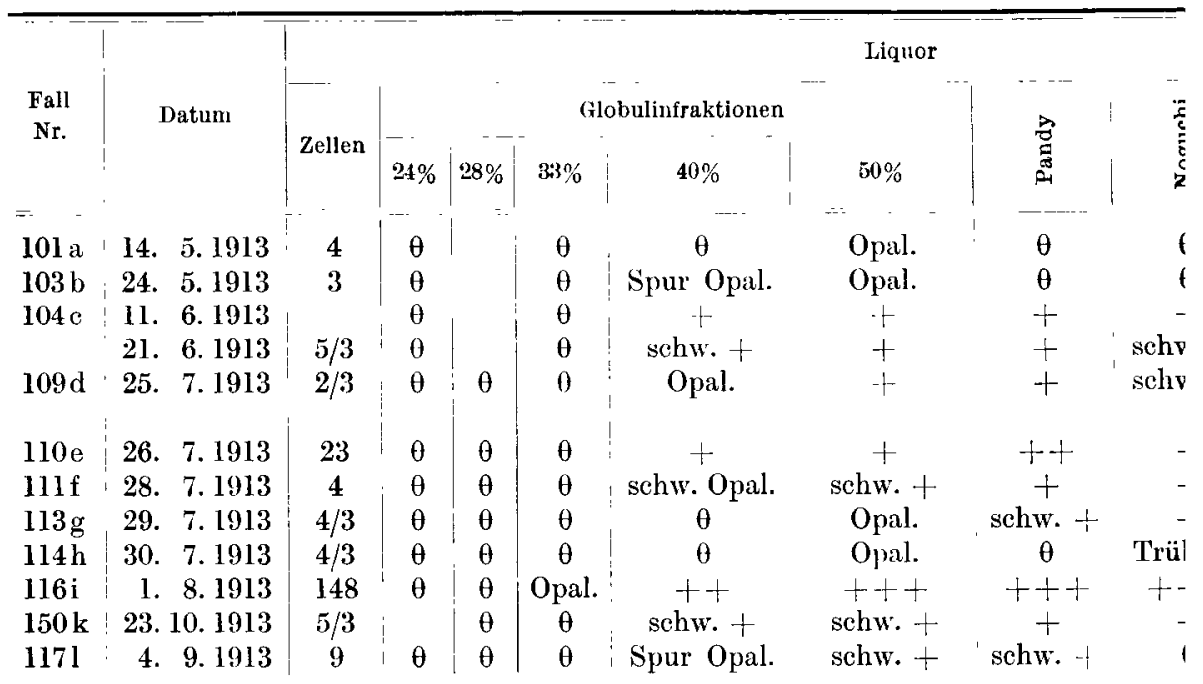

negativ werden. Der eine von uns (Kaf ka) hat auf der Breslauer Neurologentagung über dieses Phänomen berichtet. In Fall f fällt die Differentialdiagnose zwischen Lues cerebri und Paralyse schwer; während die Anamnese mehr für erstere spricht, hat der klinische Eindruck mehr für letztere gesprochen. Auffallend ist die Besserung in den Liquor- und Blutbefunden : Der Ưbertritt von Normalamboceptoren kann auf die Xanthochromie bezogen werden; Versuche haben uns gezeigt, daß zum Liquor hinzugetanes Blut positive Hämolysinreaktion hervorruft; anscheinend bleiben auch die Normalamboceptoren im Liquor ziemlich lange erhalten. 
Daß übrigens auch bei Paralysen unter Behandlung wesentliche Beeinflussungen der Reaktionsbefunde eintreten können, zeigt uns Fall h, Fall g gilt klinisch als Paralyse trotz negativer Reaktion, während bei Fall i die Differentialdiagnose zwischen Paralyse und Alkoholdegeneration noch schwankend ist.

Wir sehen, daß in jenen Fällen, in denen Normalamboceptoren in die Spinalflüssigkeit übergehen, sie wie im ersten Kapitel schon bewiesen, zu keiner Reaktion in engerem Parallelismus stehen. Auch zwischen Gesamteiweißgehalt und Globulinreaktionen sehen wir keine engeren Beziehungen. Es ist also dieses Kapitel von klinisch interes santen Fällen nicht geeignet, uns in unseren Schlüssen weiter zu führen.

\section{III.}

Wir verfügten ferner über 11 sichere Fälle von Lues cerebri. Auch hier wird es notwendig sein, die Fälle vorher klinisch zu skizzieren. Ihre Befunde sind in Tabelle $\mathrm{X}$ enthalten.

cercori.

\begin{tabular}{|c|c|c|c|c|c|c|c|c|c|c|c|c|}
\hline \multirow[b]{2}{*}{. } & \multirow[b]{2}{*}{$\begin{array}{l}\text { 产 } \\
\text { 治 }\end{array}$} & \multicolumn{4}{|c|}{$\begin{array}{l}\text { Normal Kom- } \\
\text { amboc. plement }\end{array}$} & \multicolumn{5}{|c|}{ Wassermann-Reaktion in Blut } & \multicolumn{2}{|c|}{ Wa R. im Liquor } \\
\hline & & $\stackrel{\rightleftarrows}{\Xi}$ & 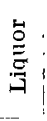 & ! & 总 & 急焉 & 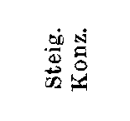 & 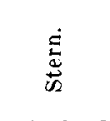 & 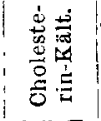 & 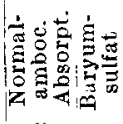 & : & 总㤩 \\
\hline$\theta$ & 0,009 & $\mathrm{f} \theta$ & $\theta$ & 100 & $\theta$ & $\theta$ & $0,5 \div+$ & $t+t$ & ++ & & $\theta$ & $\theta$ \\
\hline$\theta$ & 0,009 & 300 & $\theta$ & 200 & $\theta$ & $\theta$ & b. $1,0 \theta$ & $\theta$ & $\theta$ & & $\theta$ & b. $0, \overline{0} \theta$ \\
\hline$\theta$ & 0,018 & & $\theta$ & & $\theta$ & & & & & & $\theta$ & $0,5++$ \\
\hline - & 0,009 & 100 & 0 & 300 & $\theta$ & $+t+$ & & $++t$ & & & $\theta$ & $0,5+$ \\
\hline 一 & 0.009 & 100 & 0 & 200 & $\theta$ & $+t \cdot+$ & b. $0, \bar{s}$ & $\div++$ & $-5++$ & & $\theta$ & b. $1,0 \theta$ \\
\hline- & 0,0135 & $300_{1}^{\prime}$ & $\theta$ & $\theta$ & $\theta$ & + & $0,5++$ & & ++ & & $+t+$ & \\
\hline$\theta$ & 0,009 & 100 & $\theta$ & 100 & $\theta$ & $\theta$ & b. $1,0 \theta$ & $\theta$ & $\theta$ & & $\theta$ & b. $1,0 \theta$ \\
\hline$\theta$ & 0,009 & 400 & $\theta$ & 400 & $\theta$ & $\theta$ & b. $1,0 \theta$ & $\theta$ & & & $\theta$ & b. 1,00 \\
\hline - & 0,018 & & & & $\theta$ & & & & & & $\theta$ & b. $1,0 \theta$ \\
\hline-- & 0,0495 & 200 & $\theta$ & 300 & $\theta$ & 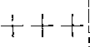 & + & $+t+$ & $+t+$ & & $t+t$ & \\
\hline . & 0,027 & & $\theta$ & & $\theta$ & +1 & & & & & $\begin{array}{l}\theta \\
\theta\end{array}$ & $0,5 \theta$ \\
\hline & & 400 & & 400 & $\theta$ & $-t+$ & & $T$ & & & & $1,0+$ \\
\hline
\end{tabular}

a) Ko. Früher völlig gesund. 1911 mit Lues infiziert. Hg-Injektion und Schmierkur. Sommer 1912: Einseitige Zuckungen in Arm und Bein, ein Mundwinkel hing schief, lallende sprache, Schwindel. Langsame Besserung. Vorübergehend verwirrt. Seit der Zeit oft schwermütig, wurde stumpfer, gab auf sein Äußeres nichts, machte sinnlose Reisen, beging Unterschlagungen. Leicht reizbar. Dezember 1912 in einem Krankenhaus: Klagen über Benommenheit; im Liquor Pleocytose, Phase 1: $\theta$, Wassermannsche Reaktion im Blute stark positiv, im Liquor bei $0,15+$, bei $0,3+\frac{1}{+}$. April 1913 Aufnahme in Friedrichsberg: Differenz der Nasolabialfalten, Pupillendifferenz, prompte Reaktion derselben, Reflexe gesteigert. Psychisch: deprimiert, unlustig, stumpf, apathisch. Eine neuerliche Untersuchung des Blutes und Liquors fand an 14. 5. 1913 statt (s. Tab. X, .r. 101). 
Impfung mit Noguchis Luetin zeigt eine sehr starke und lange bestehende Reaktion. Näßte zeitweise cin, langsam und schlecht bei der Arbeit, kritiklos, apathisch.

b) Cl. 1896 Lues. 1901 im Krankenhaus wegen Schwindelanfälle, Augenflimmern, Parästhesien, Romberg $\div$, fehlende Patellarreflexe. Diagnose: postdiphtheritische Lähmung. Wurde im Oktober gebessert entlassen, nur die Patellarreflexe fehlten noch. Im Jahre 1904 erfolgte neuerliche Aufnahme im Krankenhause: Pupillen mydriatisch, fehlende Lichtreaktion, Patellarreflexe vorhanden, Kopfschmerzen. September 1904 wurde eine totale rechtsseitige Oculomotoriuslähmung konstatiert, ferner gekreuzte Facialisparesc, Steigerung der Reflexe. Eine Lumbalpunktion ergab damals: Trübung des Liquors mit Magnesiumsulfat, Pleocytose. Nach ciner Sichmierkur besserte sich dic Ptosis r. Im Dezember neucrliche Krankenhausaufnahme: Ptosis r., Pupillen r. $>1$, lichtstarr, r. Abducenslähmung. April 1905 apoplektischer Insult. 6. Oktober 1905 in F'riedrichsberg aufgenommen. Aufnahmestatus: Oculonotoriusparese r., Facialisdifferenz, Pupillendifferenz, R. Pupille lichtstarr, Patellarsehnenreflexe r. $>1$., Romberg + , artikulatorischeKprachstörung, sensorische Aphasie. Allmähliche Besserung der körperlichen Symptome; psychisch: apathisch, interesselos, zeitweise erregt. Ende des.Jahres ein Schwindelanfall mit anschließender Benommenheit, ein andermal Zuckungen der L. Seite. 1906: Apathisch, zeitweise Schwindelanfälle mit Benommenheit oder Anfälle mit klonischen Zuckungen, zeitweise Gesichts- und Gehörtäuschungen, dabei wochselnde Stimmung, kindisch, meist apathiseh. In den Jahren 1907 und 1908 traten Anfälle mit Erbrechen und aphasisch-paraphrasische Störungen auf, meist stumpf. Weiterhin stationäres Befinden. Kerologische und sonstige Befunde in Liquor und Blut negativ (Tab. X, Nr. 103).

c) Ha. Soll schon mit 20 Jahron (1897) Anfälle gehabt haben (?). 1901 seien sie weggeblieben. 1902 geheiratet, seit 1904 auffällig. 1910 im Krankenhause: Hysterie, Anämie, mäßige Intelligenz. Bei einer zweiten Aufnahme $1912 \mathrm{im} \mathrm{Kran-}$ kenhause: Eindruck leichter Demenz, Pupillen ungestört. Nach Friedrichsberg verlegt fand sich: Pupillen, Facialis ungestört, Steigerung aller Reflexe, Schwäche beider Beine, apathisch, weinerlich, erregt, verwirrt. Im August wurde eine Neuritis optica konstatiert. P. wurde allmählich stumpf, indolent, dement, zeitweise verwirrt mit Konfabulationen. Die serologisehen Reaktionen waren stark positiv. Wegen der Neuritis optica wurde 1912 der Balkenstich gemacht, es traten nachler Krämpfe, dann aber Besserung des Visus auf. Relativ stationäres psychisches Verhalten. Mann: Stern +. Letzte Untersuchung des Blutes und Liquors s. Tab. X, Nr. 104. Auffallend war die starke Selbsthemmung im inaktiven Serum und Liquor.

d) Kr. 1908 Unfall. Nachher Kopfschmerzen, Vergeßlichkeit. Januar 1911 wurde Pupillendifferenz, träge Pupillenreaktion, langsame schwerfällige Sprache. gesteigerte Kniereflexe konstatiert. Er wurde vom 2.-10. 11.1911 zur Beobachtung zweeks Ausstellung eines Unfallgutachtens der Irrenanstalt Friedrichsberg überwiesen. Hier fand sich Pupillendifferenz, etwas herabgesetzte Lichtreaktion, sehr lebhafte Reflexe; psychisch stumpf, Herabsetzung der Merkfähigkeit. K. wurde am 12. Februar 1913 wieder aufgenommen, da er seine Frau mißhandelt hatte. Er war körperlich nicht verändert, psychisch zeigte sich Stumpfheit, nicht zu weitgehende und stationäre Demenz; Luctinreaktion: schwach positiv, Liquor und Blutbefunde s. Tab. X.

e) Ol. August 1901 in Friedrichsberg aufgenommen. Pupillen eng, prompt reagierend, Patellarsehnenreflexe lebhaft. Psychisch: apathisch, mutistisch, zeitweise manische Erregung. Im .Jahre 1902 wurde Ungleichheit der träge auf Lichteinfall reagierendes Pupillen konstatiert. 1903 maniwche Attacken. Pupillen fast lichtstarr. 
1905 trat allmählich geistige St umpfheit, Unsauberkeit auf. 1908 Pupillendifferenz, lichtstarr. Läppisch-dement. 1909 periphere Arteriosklerose, Zunge nach R abgewendet, Reflexe gesteigert, Hypalgesie. 1910 wurde Nystagmus konstatiert. Stationäres Verhalten.

f) Schü. 1897 zum erstenmal aufgenommen; still, stumpf; somatisch: Facialisparese 1., Silbenstolpern. Bei der zweiten Aufnahme 1897 stumpf, verblödet, stark gesteigerte Patellarsehnenreflexe, Romberg +, Ataxie, Pupillen entrundet, träg reagierend. 1899 Anfall. Stumpf. 1906 Anfall mit Zuckungen. Weiter stationäre Befunde, Zunge nach 1. gewendet, Sprachstörung, Reflexe gesteigert, Gang apathisch, ataktisch. November 1910 Krampfanfall. 1911 Krampfanfall mit Amnesie, Facialisparese, einmal Krampfanfall mit linksseitigen Zuckungen. Auch späterhin noch Anfälle. Stationärer Befund.

g) Heg. 1904 wegen Lues cerebri in Krankenhausbehandlung. Venerische Infektion zugegeben. Im Alter von 35 Jahren Kopfschmerzen und zweimal ein apoplektiformer Zustand. Befund: 1904: Kopfschmerzen, Pupillen eng, träge reagierend, Zunge nach r. abweichend, fibrilläre Zuckungen der Mundmuskulatur, Parästhesien im Gesicht und am r. Arm. Patellarreflexe lebhaft gesteigert, r. $>1$. R. Fußklonus. Psychisch: Deprimiert, grübelnd. Traitement mixte. Nachher wieder zur See gefahren. Später Abnahme der Intelligenz. In Friedrichsberg aufgenommen Januar 1905: Vibrieren der Mundmuskulatur, Zunge grobschlägiger Tremor, Pupillen prompt reagierend, lebhaft gesteigerte Reflexe, Patellarklonus. Patellarsehnenreflexe r. $>1$. Romberg + . Ataxie. Artikulatorische Sprachstörung. Psychisch: apathisch, gehemmt, verwirt, stumpf. Zum zweiten Male wurde er März 1906 wegen Aufregungszuständen und Verwirrtheit aufgenommen. Gang ataktisch, Sprache stark gestört, vorgeschrittene Demenz, wechselndes Verhalten, meist ruhig, stumpf, euphorisch. Pupillen entrundet, sehr wenig auf Licht rcagierend, Gang taumelnd. 1908, 1909: Dement, zeitweilig erregt, hinfällig. 1912 unverändertes Bild, Sprache verwaschen die bulbäre. Serologische Befunde früher wechselnd, jetzt negativ (s. Tab. X, Nr. 113).

h) Kreuz. Luetische Infektion 1894. 1906 Schlaganfall mit Lähmung der r. Seite. Friedrichsberg: Dezember 1909. Befund: Parese der M. Seite, Facialis l. gelähmt, Lunge nach l. abweichend, Pupillen ohne Befund. Reflexe r. $>1$. Psychisch: dement, verwirrt, euphorisch. Schrift unsicher, Sprache gestört. 1910, 1911, 1912 stationär, stumpf, freundlich, nicht weitgehend dement.

i) Hau. 1902 luische Infektion. 1903-1904 in Kiel Schmierkuren, später in Hamburg Jod. 1907 linksseitige Hemiplegie und vorübergehende Sprachstörung, Gedächtnisschwäche. 1909 Hemiplegie, Schmierkur. Psychisch reizbar, verschwenderisch, sinnlose Handlungen. 1910 Befund: L. Facialisparese, Ptosis beiderseits, Pupillen r. $>$ l., träge reagierend, spastische Parese der 1. Seite, 1. Hypästhesie und Hypalgesie. Reflexe gesteigert 1. > r. Psychisch: euphorisch, Urteilsschwäche, Merkfähigkeitsstörung, Stimmungswechsel, zeitweise stumpf. In Friedrichsberg seit Oktober 1910. Sprache leicht artikulatorisch gestört. Dezember 1910 Wassermannsche Reaktion im Blut und Liquor stark positiv, Phase 1: Zellen 2. Nach Salvarsan keine Veränderung. Weiter stationäres Verhalten, freundlich, euphorisch, nicht weitgehend dement. Letzte serologische Befunde (s. Tab. X, Nr. 116).

k) Dic Spinalflüssigkeit entstammt einem Falle des Eppendorfer Krankenhauses, die uns liebenswürdigerweise überlassen wurde.

1) Bu. Seit mehreren Jahren stellungs- und obdachlos; in den letzten Jahren 12 mal wegen Diebstahl, Bettelei usw. bestraft. Zuletzt in Fuhlsbüttel. Hier begannen Halluzinationen und verworrene Wahnideen. Deshalb wurde er am 12. August 1913 nach Friedrichsberg überführt. Aufnahmebefund: Pupillendifferenz und 
minimale Lichtreaktion, stark gesteigerte Reflexe, Tremores- psychisch: zerfahren, stark halluzinierend, erregt.

Bevor wir auf die Besprechung der Fälle eingehen, sei darauf hingewiesen, daß die sichere Diagnose der Lues cerebri besonders in ihren späteren Stadien immer schwieriger wird, und wie die Literatur zeigt, die Ansichten verschiedener Autoren beträchtlich divergieren. Es hat dies nicht zumindest darin seinen Grund, daß das Krankheitsbild der Paralyse heute meist nicht mehr das klassische Bild zeigt. Wir können atypische Fälle aller Art sehen, stationäre Formen sind nicht selten, ebenso Kombinationen mit luischen Veränderungen, auch scheint es, wie A. Jakob in Altona hervorgehoben hat, auch Fälle zu geben, die histologisch eine engere Verwandtschaft zur Lues cerebri zeigen. Es ist daher heute mehr denn je die Mitarbeit der Anatomie notwendig. Es soll nun nicht Zweck dieser Arbeit sein, auf Grund von serologischen Befunden Diagnosen stellen zu wollen. Es lag uns immer am Herzen, der Klinik und der Anatomie den Vortritt zu lassen. In dieser Arbeit soll in erster Linie auf die relativen Beziehungen zwischen verschiedenen Krankheitsgruppen eingegangen werden.

Dies vorausgeschickt muß hervorgehoben werden, da $\beta$ von seiten der Ärzte, die die einzelnen Fälle klinisch durch lange Zeit beobachtet haben, in jedem der einzelnen Fälle die Diagnose auf sichere Lues cerebri gestellt worden ist. Es ist sehr schwierig, in einer kurzen Skizze Krankheitsbilder so zu schildern, daß der Leser auch gleich den gewünschten Eindruck erhält.

Es käme im übrigen in Fall c) ein Tumor cerebri differentialdiagnostisch in Betracht, wogegen besonders der Liquorbefund spricht, in den Fällen e) und g) könnte noch an eine atypische Paralyse gedacht

Tabelle XI.

\begin{tabular}{|c|c|c|c|c|c|c|c|c|c|}
\hline \multirow{3}{*}{$\begin{array}{c}\text { Fall } \\
\text { Nr. }\end{array}$} & \multirow{3}{*}{ Datum } & \multirow{3}{*}{ Zellen } & \multicolumn{7}{|c|}{ Liquor } \\
\hline & & & \multicolumn{5}{|c|}{ Globulinfraktionen } & \multirow{2}{*}{ 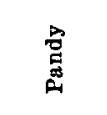 } & \multirow{2}{*}{ 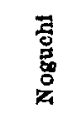 } \\
\hline & & & $24 \%$ & $28 \%$ & $33 \%$ & $40 \%$ & $50 \%$ & & \\
\hline $119 \mathrm{a}$ & 6. 5. 1913 & $1 / 3$ & $\theta$ & & $\theta$ & $\theta$ & Spur Opal. & $\theta$ & $\theta$ \\
\hline $125 \mathrm{~b}$ & 12. 6.1913 & $\theta$ & $\theta$ & & $\theta$ & $\theta$ & Spur Opal. & Opal. & $\theta$ \\
\hline $126 \mathrm{c}$ & 13. 6.1913 & $4 / 3$ & $\theta$ & & $\theta$ & $\theta$ & $\theta$ & $\theta$ & $\theta$ \\
\hline $137 \mathrm{~d}$ & 4. 7.1913 & 1 & $\theta$ & & $\theta$ & $\theta$ & Spur Opal. & Spur & Spur \\
\hline $138 \mathrm{e}$ & 4. 7.1913 & $2 / 3$ & $\theta$ & & $\theta$ & $\theta$ & $\theta$ & $\theta$ & $\theta$ \\
\hline $139 \mathrm{f}$ & 10. 7.1913 & $2 / 3$ & $\theta$ & & $\theta$ & $\theta$ & $\theta$ & $\theta$ & $\theta$ \\
\hline $140 \mathrm{~g}$ & 29. 7.1913 & $2 / 3$ & $\theta$ & $\theta$ & $\theta$ & schw. Opal. & schw. Opal. & Spur & Spur \\
\hline $141 \mathrm{~h}$ & 5. 8.1913 & 3 & $\theta$ & $\theta$ & $\theta$ & $\theta$ & Spur Opal. & $\begin{array}{c}\text { leichte } \\
\text { Opal. }\end{array}$ & $\theta$ \\
\hline $142 \mathrm{i}$ & 6. 8. 1913 & $4 / 3$ & $\theta$ & $\theta$ & $\theta$ & $\theta$ & Spur Opal. & $\theta$ & $\theta$ \\
\hline $149 \mathrm{k}$ & 21.10 .1913 & $1 / 3$ & $\theta$ & $\theta$ & $\theta$ & $\theta$ & $\theta$ & $\theta$ & $\theta$ \\
\hline
\end{tabular}


werden. Dies auch angenommen, würde sich doch nichts an dem ändern, was wir zu diesen Fällen zu sagen haben. In allen Fällen fehlt Normalamboceptor im Liquor, trotzdem er im Blute genügend stark (zweimal 400 zweimal 300, einmal 200, dreimal 100) vorhanden ist, trotzdem die PhaseI immer positiv ist (Opalescenz 5 mal, schwach positiv 3 mal, +3 mal, $+++1 \mathrm{mal})$. Auch die drei Fälle mit gesteigertem Gesamteiweißgehalt weisen keinen Amboceptorübertritt auf (116, 117, 150). Ähnliche Beziehungen wie zu Phase I finden sich zu Pandy und Noguchi. Die Braun-Huslersche Reaktion ist nur einmal in dem eiweißreichsten Falle positiv. Die Wassermannsche Reaktion ist 2 mal im Liquor stark positiv (110, 116), 2 mal bei 0,5 oder $1,0(103,117)$. Bei 33 proz. Ammoniumsulfatsättigung tritt nur einmal in dem eiweißreichsten Fall Opalescenz auf, bei 40 proz. Sättigung ist aber in der großen Mehrzahl der Fälle eine positive Reaktion zu konstatieren und diese Phänomen bilden zusammen mit der positiven Phase $I$ in vielen Fällen das einzig Pathologische (103, 111, 113).

Úber die Konsequenzen, die sich aus dem Vergleich der oben geschilderten Befunde mit jenen bei Paralyse ergeben, wird später zu reden sein.

IV.

10 Fälle von Lues ohne sicher vorhandene luische Erkrank ung des Z. N.S. wurden weiter von uns untersucht. Hierher gehören sechs Fälle von Alkoholismus bei latenter Lues (Tab. XI, Nr. 119, 125, 137, 138, 139, 141), ferner zwei Fälle von Dementia praecox + Lues latens (Tab. XI, Nr. 126, 140), eine Hemiplegie und ein Depressionszustand mit Lues. Phase I muß bis auf Fall Nr. 140 als negativ angesehen werden (Spur Opalescenz). In Fall Nr. 140 bestand früher Pupillen-

Lues.

\begin{tabular}{|c|c|c|c|c|c|c|c|c|c|c|c|c|c|c|}
\hline \multirow[b]{2}{*}{ 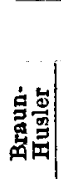 } & \multirow[b]{2}{*}{ 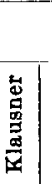 } & \multirow[b]{2}{*}{$\begin{array}{l}\text { 要 } \\
\frac{2}{2}\end{array}$} & \multicolumn{2}{|c|}{$\begin{array}{l}\text { Normal- } \\
\text { amboc. }\end{array}$} & \multicolumn{2}{|c|}{$\begin{array}{c}\text { Kom- } \\
\text { plement }\end{array}$} & \multicolumn{6}{|c|}{ Wassermann-Reaktion im Blut } & \multicolumn{2}{|c|}{ Wa.R. im Liquor } \\
\hline & & & 芦 & 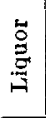 & $\stackrel{\vec{\Xi}}{m}$ & 峁 & 㻤 & 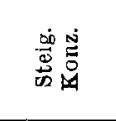 & 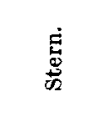 & 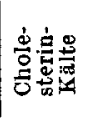 & 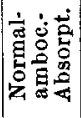 & 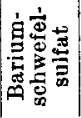 & 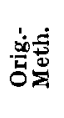 & 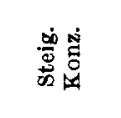 \\
\hline$\theta$ & $\theta$ & & 300 & $\theta$ & 300 & $\theta$ & $\theta$ & b. $1,0 \theta$ & +++ & $+t$ & cur. & $\theta$ & $\theta$ & b. $1,0 \theta$ \\
\hline$\theta$ & $\theta$ & 0,0135 & 300 & $\theta$ & 100 & $\theta$ & +++1 & & $+t+$ & $t+t$ & & & $\theta$ & b. $1,0 \theta$ \\
\hline$\theta$ & $\theta$ & 0,009 & 400 & $\theta$ & 200 & $\theta$ & $\theta$ & b. $0,5 \theta$ & $t+t$ & $t+t$ & & & $\theta$ & b. $1,0 \theta$ \\
\hline$\theta$ & $\theta$ & 0,0225 & 400 & $\theta$ & 400 & $\theta$ & $\theta$ & b. $0,5 \theta$ & $\theta$ & + & & & $\theta$ & b. $1,0+$ \\
\hline$\theta$ & $\theta$ & 0,009 & & $\theta$ & & $\theta$ & & & & & & & $\theta$ & b. $1,0 \theta$ \\
\hline$\theta$ & $\theta$ & 0,009 & 400 & $\theta$ & 400 & $\theta$ & +++ & $++t$ & +++ & & & & $\theta$ & b. $1,0 \theta$ \\
\hline$\theta$ & $\theta$ & 0,0045 & 400 & $\theta$ & 400 & $\theta$ & $\theta$ & b. $1,0 \theta$ & $\theta$ & & & & $\theta$ & b. 1,00 \\
\hline$\theta$ & $\theta$ & 0,0135 & & $\theta$ & & $\theta$ & & & & & & & $\theta$ & b. $1,0 \theta$ \\
\hline$\theta$ & & 0,018 & 400 & $\theta$ & 400 & $\theta$ & $t+t$ & & +++ & $+t+$ & & & $\theta$ & b. $1,0 \theta$ \\
\hline$\theta$ & $\theta$ & 0,027 & 300 & $\theta$ & 300 & $\theta$ & $\theta$ & b. $0,5 \theta$ & $\theta$ & $\theta$ & & & $\theta$ & b. $1,0 \theta$ \\
\hline
\end{tabular}


störung, hier ist auch auffällig, daß Pandy und Noguchi eine Spur positiv waren, ohne Erhöhung des Gesamteiweißgehaltes. Ein gleiches Verhalten fand sich auch im Fall Nr. 137. Dieser Fall war auch wegen der bei 1,0 positiven Wassermann Reaktion einer luischen Hirnerkrankung verdächtig, wofür auch Pupillenstörungen sprachen, doch konnte die klinische Beobachtung weiter keine Symptome dafür erbringen. Dieser Fall ist übrigens wieder entlassen. $\mathrm{Ob}$ die beiden Opalescenz anzeigenden Pandy Reaktionen in Fall Nr. 125 und 141 pathologisch aufzufassen sind, muß dahingestellt bleiben, weiter auch die Frage, ob sie, wenn pathologisch, auf die Lues zu beziehen sind. Die Tabelle zeigt uns ferner wieder, wie gering die Beziehung zwischen Globulinreaktionen und Gesamteiweißgehalt sind: der eiweißreichste Fall (Nr. 149) zeigte alle Reaktionen glatt negativ, der eiweißärmste (Nr. 140) die schon besprochenen leicht positiven Reaktionen. Daß weder in Fall Nr. 149 trotz des gesteigerten Eiweißgehaltes und genügender Amboceptormenge, noch in den Fällen mit leicht positiven Globulinreaktionen auch nur eine Spur Amboceptorübertritt stattfand, braucht wohl nicht besonders hervorgehoben zu werden.

$$
\text { V. }
$$

In dem letzten Abschnitte seien Fälle aller Art besprochen, die nichts mit Lues zu tun haben (Tab. XII). Es sind 19 Fälle: Nr. 124

Tabelle XI

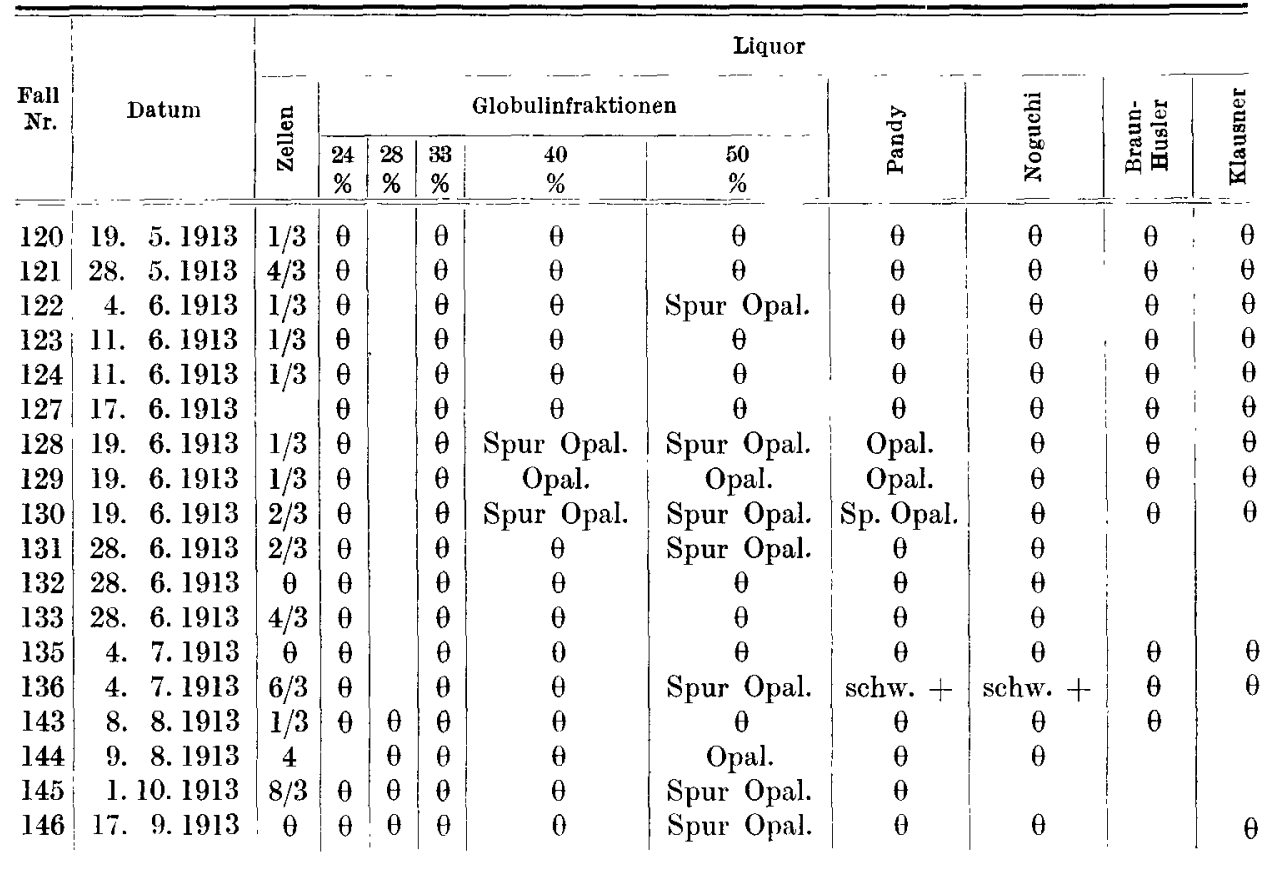


galt als nicht krank, Nr. 121, 122, 123, 130, 131, 132, 133, 144 stellen Dementia praecox Fälle dar, Nr. 135, 145 gehören dem Gebiete des Alkoholismus an, Nr. 127, 128, 129, 130, 142 sind Arteriosklerosen, die letzten beiden mit Apoplexie, Nr. 143 ist eine Epilepsie, Nr. 146 eine $\mathrm{Hutingtonsche} \mathrm{Chorea.} \mathrm{Außerdem} \mathrm{gehörte} \mathrm{unserem} \mathrm{Materiale} \mathrm{noch}$ eine fragliche Tabes an, deren Befunde die folgenden waren.

Zellen: 3.

Globulinfraktionen im Liquor: $24 \% \theta$

$$
\begin{aligned}
& 28 \% \theta \\
& 33 \% \\
& 40 \% \\
& 50 \% \text { Opal. } \\
& 50 \% \text { Opal. }
\end{aligned}
$$

Pandy: +

Noguchi: +

Gesamteiweiß: 0,009\%

Normalamboceptor im Blute $\theta$, im Liquor $\theta$

Komplement im Blute $\theta$, im Liquor $\theta$

Wassermannsche Reaktion Blut mit allen Verf. $\theta$

Liquor bis $1,0 \theta$.

\begin{tabular}{|c|c|c|c|c|c|c|c|c|c|c|c|c|}
\hline \multirow[b]{2}{*}{$\begin{array}{l}\vec{D} \\
.7 \\
\vec{Z}\end{array}$} & \multicolumn{2}{|c|}{$\begin{array}{c}\text { Normal- } \\
\text { amboceptor }\end{array}$} & \multicolumn{2}{|c|}{$\begin{array}{c}\text { Komple- } \\
\text { ment }\end{array}$} & \multicolumn{6}{|c|}{ Wassermann-Reaktion im Blut } & \multicolumn{2}{|c|}{ Wa R. im Liquor } \\
\hline & $\stackrel{\Xi}{\Xi}$ & | & $\vec{B}$ & 岑 & 这密 & 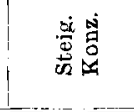 & 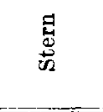 & 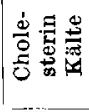 & 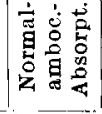 & 鸹密 & 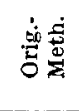 & 岂 \\
\hline 0,009 & -- & 0 & $\cdots$ & 0 & & & & & & & $\theta$ & b. $1,0 \theta$ \\
\hline 0,018 & 400 & 0 & 400 & $\theta$ & 0 & b. $1,0 \theta$ & $\theta$ & $\theta$ & & & & \\
\hline 0,0045 & 400 & $\theta$ & 300 & $\theta$ & $\theta$ & b. $1,0 \theta$ & $\theta$ & $\theta$ & & & $\theta$ & b. $0,5 \theta$ \\
\hline 0,0045 & 300 & $i \theta$ & 200 & $\theta$ & () & b. $0,5 \theta$ & $\theta$ & $\theta$ & & & $\theta$ & b. $1,0 \theta$ \\
\hline 0,009 & & $\theta$ & & $\theta$ & & ! & & & $!$ & & 0 & b. $1,0 \theta$ \\
\hline 0,009 & $\theta$ & $\theta$ & 200 & $\theta$ & $\theta$ & b. $0,5 \theta$ & $+t+$ & $\theta$ & & & $\theta$ & b. $1,0 \theta$ \\
\hline 0,0225 & $\theta$ & $\theta$ & $\theta$ & $\theta$ & $\theta$ & b. $0,5 \theta$ & $\theta$ & & & & 0 & b. $1,0 \theta$ \\
\hline 0,027 & 100 & $\theta$ & 300 & $\theta$ & $\theta$ & b. $0,5 \theta$ & $\theta$ & $\theta$ & & & $\theta$ & b. $1,0 \theta$ \\
\hline 0,0135 & () & 0 & 100 & $\theta$ & $\theta$ & b. $0,5 \theta$ & $\theta$ & & & & $\theta$ & b. $1,0 \theta$ \\
\hline 0,018 & & 0 & & $\theta$ & & & & & & & $\theta$ & b. $0,5 \theta$ \\
\hline 0,0045 & & $\theta$ & & $\theta$ & & 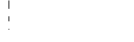 & & & 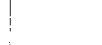 & & $\theta$ & b. $0, \tilde{5} \theta$ \\
\hline 0,009 & & $\theta$ & & $\theta$ & & & & & & & $\theta$ & b. $0,5 \theta$ \\
\hline 0,009 & 300 & $\theta$ & 200 & $\theta$ & $\theta$ & b. 0,50 & $\theta$ & $\theta$ & 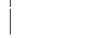 & & $\theta$ & b. $1,0 \theta$ \\
\hline 0,0225 & 200 & $\theta$ & 400 & $\theta$ & $\theta$ & $1,0 \theta$ & $\theta$ & $\theta$ & & & $\theta$ & b. $1,0 \theta$ \\
\hline 0,0135 & 100 & 0 & 100 & & $\theta$ & b. $0,5 \theta$ & 0 & $\theta$ & 1 & & $\theta$ & b. $1,0 \theta$ \\
\hline 0,0225 & & $\theta$ & & $\theta$ & $\theta$ & b. $0,5 \theta$ & $\theta$ & $\theta$ & 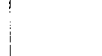 & & $\theta$ & $\begin{array}{l}\text { b. } 1,0 \theta \\
\text { b. } 1,0 \theta\end{array}$ \\
\hline 0,018 & 400 & $\theta$ & 400 & 0 & $\theta$ & 0,50 & $\theta$ & $\theta$ & 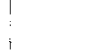 & & 0 & b. $1,0 \theta$ \\
\hline
\end{tabular}

Der nach Pandy und Noguchi schwach positive Fall Nr. 136, der übrigens bei Phase I nur Spur Opalescenz zeigt, ist eine Hemi-

Varia.

Z. f. d. ges. Neur. u. Psych. O, XXII, 
plegie bei Arteriosklerose. Da hier auch der Gesamteiweißgehalt kaum nennenswert gesteigert ist, beweist dieser Fall, wie notwendig auch neben der Phase I die Anstellung anderer Globulinreaktionen ist. Fälle Nr. 128 und 129, in denen schon bei $40 \%$ Ammoniumsulfatfraktion Opalescenz auftritt und in denen auch $\mathrm{Pandy}$ Opalescenz zeigt, sind ebenfalls Arteriosklerosen. Fälle Nr. 122, 130, 131, 144, 145, 146 zeigen uns, daß auch auf dem Gebiete der Dementia praecox, des Alkoholismus und anderen Krankheiten ganz schwache Phase I vorkommt, wobei auffallenderweise auch einmal Nr. 13 eine ganz geringe $\mathrm{Pa}$ ind yreaktion auftritt. Die positive Sternsche Reaktion in Fall Nr. 127 ist wohl unspezifisch. Einen etwas gesteigerten Gesamteiweißgehalt können wir nur in Fall Nr. 129 feststellen (Arteriosklerose, Alkoholismus, Epilepsie). Sonst bieten die Fälle nichts Neues; in Fall Nr. 121 findet sich im Liquor auffallenderweise Eigenhemmung.

\section{Diskussion der Ergebnisse.}

Nach unseren Zusammenstellungen beträgt der normale Eiweißgehalt der Spinalflüssigkeit bis 0,025 resp. 0,03\%; das Minimum liegt aber tiefer, als es bisher angenommen wurde, auch bei Paralysen kann, wenn auch anscheinend sehr selten, der Gesamteiweißwert unter 0,01\% sinken; meist betragen die geringsten Werte hier etwa $0,02 \%$. Wir konnten ferner erweisen, daß zwischen Gesamteiweißgehalt und Globulinreaktionen nur ein ganz grober Zusammenhang besteht, insofern aber ganz negative Fälle geringe Eiweißwerte, stark positive am häufigsten höhere Eiweißwerte haben, daß sich eine weiterer Parallelismus nicht stiften läßt. Dies gilt auch für die durch verschiedenprozentige Ammoniumsulfatsättigung ausfüllbaren Globulinfraktionen. Zwischen den verschiedenen Reaktionen der Pandyschen, Noguchischen und Phase I besteht ein leichter Parallelismus, der aber oft nach der einen oder der anderen Seite überschritten wird. In vielen Fällen macht es den Anschein, als würde die Pandysche Reaktion die feinste sein, d. h. bei der geringsten Erhöhung des Gesamteiweißgehaltes auftreten. Es ist aber schon aus dem Gesagten klar, daß sich Beziehungen zwischen dem Gesamteiweißgehalt und der Pandy-Reaktion nicht gewinnen lassen, da die letztere nur eine Vermehrung einer bestimmten Gruppe von Eiweißstoffen anzeigt. Immerhin scheint sie diese letztere aber sehr scharf anzuzeigen und diese Rolle wird ihr nur in manchen Fällen von der Phase I strittig gemacht; es wird daher nötig sein, in manchen Fällen, besonders bei der Kontrolle von Heilerfolgen, beide Reaktionen heranzuziehen. Die Noguchi-Reaktion bleibt an Bedeutung hinter beiden zurück. Der Braun-Huslerschen Reaktion wohnt insofern Bedeutung bei, als sie bei Paralysen auch bei geringer Eiweißvermehrung vorkommt, bei anderen Fällen jedoch nur bei stark vermehrtem Ei- 
weißgehalt, ihr daher eine Rolle bei der Paralysendiagnose nicht abzusprechen ist. Eine besonders interessante Stellung nehmen jene Resultate ein, die durch die Ausfällung mit steigenden Ammoniumsulfatkonzentrationen erhalten wurden. In der Paralysegruppe sehen wir bei 33 proz. Sättigung in 82 von 100 Tällen, also in $82 \%$ schon Fällung auftreten und dies bei Gesamteiweißwerten verschiedenster Größe. Vergleichen wir hierzu die Tabelle der Lues cerebri, so finden wir eine derartige Ausfällung nur einmal bei relativ hohem Eiweißgehalt von etwa ${ }_{1}^{1} / 2 \% 0$. Wir haben, wie schon besprochen, Versuche angestellt, indem wir zu den gleichen Liquormengen $(1 \mathrm{cem})$ steigende Konzentrationen von Ammoniumsulfat von $24 \%-35 \%$ zusetzten, nachdem wir vorher

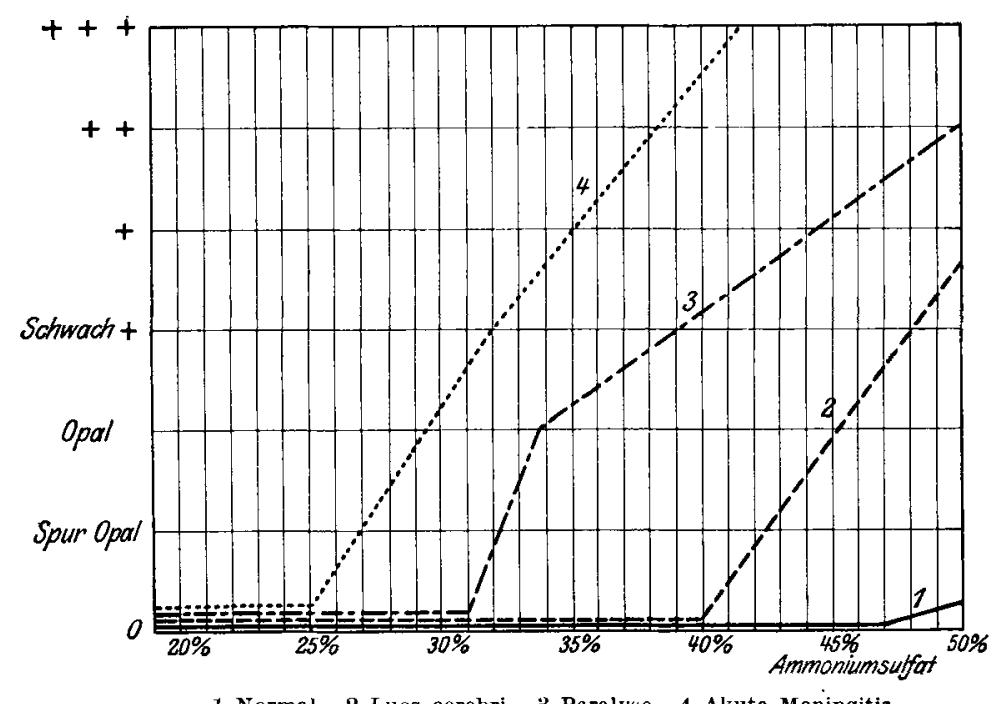

1 Normal, 2 Lues cerebri. 3 Paralyse 4 Akute Meningitis.

Fig. 1.

mit destilliertem Wasser aufgefüllt hatten. Wir fanden so, daß diese Ausfällung bei $30-33 \%$ beginnt also mit Fibrinogen nichts zu tun hat. Für dieses letztere, das ja bei 19-28 proz. Ammoniumsulfatsättigung ausfällt, stellt besonders die akute Meningitis das Gebiet dar, wie wir schon an anderer Stelle berichtet haben ${ }^{8}$ ). Grob schematisch lassen sich daher die Ausfällungskurven für den normalen Liquor ${ }^{1}$ ), ferner jenen bei Lues cerebri ${ }^{2}$ ), bei Paralyse ${ }^{3}$ ) und akuter Meningitis ${ }^{4}$ ) in Figur 1 darstellen. Aus der Figur ergibt sich die hohe diagnostische Bedeutung der Ammoniumsulfuricumausfällungen; während die Phase I die $50 \%$ Sättigung bei allen mit Entzündung der Meningen einhergehenden Fällen positiv ist, finden wir bei Paralyse die beginnendeA usfäll ung schon bei $33 \%$, bei Meningitis meist bei $24-28 \%$. Auch theoretisch sind 
die Kurven sehr interessant, sagen sie uns doch manches über die physiologische Stellung des normalen und pathologischen Liquors innerhalb der Körperflüssigkeiten; eine Kurve wie sie z. B. der meningitische Liquor bietet, finden wir ähnlich, wenn auch steiler, bei der Ascitesflüssigkeit, bei der Blutegelextraktlymphe $\mathbf{u}$. a.; wir müssen also tatsächlich aus der Kurve schließen, daß es sich hier wesentlich um Transsudat resp. Exsudat handelt, welches aber dem Liquor beigemischt ist. Je geringer nun die Beimengung ist, desto später setzt die Kurve einund die des normalen Liquors beweist wieder dadurch, daß sie sich fast gar nicht von der Abscisse abhebt, die Sonderstellung der Spinalflüssigkeit, welche sie nur bis zu einem gewissen Grade mit der Flüssigkeit der vorderen Kammer teilt. Wir können auch, wenn wir uns der Nomenklatur mancher Chemiker bedienen, sagen: bei gewöhnlichen Formen der Lues cerebri findet sich Pseudoglobulin und Globulin vermehrt, bei der Paralyse Euglobulin, Pseudoglobulin und Globulin, bei der akuten Meningitis Fibrinoglobuline, Euglobulin, Pseudoglobulin, und Globulin (ohne damit aussagen zu wollen, daß es sich hier um differente chemische Körper handelt).

Nun wollen wir zur Besprechung der Beziehungen zum Utbertritt von Normalamboceptor und Komplement in die Spinalflüssigkeit übergehen. Wir konnten unter 95 Paralysefällen $84 \mathrm{mal}$ $(88 \%)$ Ubertritt von Normalamboceptoren bei genügend hohem Serumtiter feststellen, zweimal war ein negativer Normalamboceptorenbefund durch fehlenden Zwischenkörper im Serum erklärt, 4 mal war aber trotzdem hämolytischer Normalamboceptor im Liquor nachzuweisen. Die Stärke des Übertrittes war, wie schon Tabelle VII gezeigt hat, $1 / 200-1 / 12$; die dort skizzierten Werte $2,4,8$ sind natürlich nur relativ brauchbar; sie entsprechen jenen Fällen, in denen im Blutserum hämolytischer Amboceptor nicht nachweisbar war; es ist aber noch nicht bewiesen, daß er wirklich nicht vorhanden ist (Boas und Neve). Wir wollen daher $1 / 12$ als vorläufiges Maximum des Amboceptorübertrittes ansehen.

Wir haben schon ausführlich gezeigt, daß innerhalb der Paralyse ein Parallelismus zwischen Gesamteiweiß, Globulinreaktionen einerseits Amboceptorübertritt andererseits, auch nicht in groben Zügen nachweisbar ist. Die untersuchten Fälle von Lues cerebri und alle anderen zeigten, trotz mehrfach erhöhten Gesamteiweißgehaltes und öfter positiver anderer Reaktionen nie Amboceptorgehalt in der Spinalflüssigkeit. Nur die bei 33 proz. Ammoniumsulfatsättigung gefällte Globulinfraktion - die Euglobulinfraktion - zeigte einen gewissen Parallelismus mit dem Amboceptorübergang. Wir haben daher Versuche angestellt, die diese Beziehungen noch weiter beleuchten sollen. Vorläufig sei nur berichtet, daß in einem Fall, in dem wir die Euglobulin- 
fraktion des Liquors abfiltriert hatten, die Hämolysinreaktion der vorbehandelten Spinalflüssigkeit schwächer war als die des unveränderten Liquors.

Immerhin aber gibt es genug Fälle, in denen der bezeichnete Parallelismus nicht besteht, so daß enge Beziehungen auch hier in dem Sinne, daß der Normalamboceptor in der Euglobulinfraktion enthalten ist, wohl nicht anzunehmen sind. Komplement fand sich unter unseren 100 Paralysen 7 mal (7\%), bis auf Fall Nr. 10 (Tab. V) immer mit dem bei Paralysen vorkommenden Maximum vom Normalamboceptor verknüpft; in Fall Nr. 10 beträgt aber auch der Amboceptorübergang $1 / 25$. Beziehungen zu einer bei $19-28$ proz. Sättigung fällbaren Globulinfraktion waren nicht nachzuweisen, auch die 33 proz. Fraktion war in den Komplementfällen nicht sehr stark. Diese Befunde sprechen gegen die Beziehungen, wie sie Zaloziecki zwischen Fibrinogen und Komplementübergang gestiftet hat.

Wir können für die Verhältnisse, wie sie bei den verschiedenen Krankheiten bestehen, im folgenden einen zweckmäßigen Ausdruck festsetzen, der uns für die Definierung des Begriffes der erhöhten Permeabilität von Nutzen sein kann. Nehmen wir folgende Bezeichnungen an: für den Normalamboceptorgehalt des Liquors, wie schon einmal mitgeteilt:

$\begin{array}{lr}++++ & 10 \\ +++ & 8 \\ ++ & 6 \\ + & 4 \\ \text { sehw. } & 3 \\ \text { Sp. } & 2 \\ \theta & 1\end{array}$

und die gleichen Zahlen auch für die Stärke der verschiedenen Globulinreaktionen, während wir das Gesamteiweiß so ausdrücken:

$\begin{array}{cccc}0,1 \% & \text { und } & \text { mehr } & 10 \\ 0,08 \% & , & , & 8 \\ 0,06 \% & , & , & 6 \\ 0,04 \% & , & , & 4 \\ 0,03 \% & , & , & 3 \\ 0,02 \% & , & , & 2 \\ 0,01 \% & , & , & 1\end{array}$

so können wir das Verhältnis des Normalamboceptorgehaltes zum Globulingehalt (ausgedrückt z. B. durch Phase I) durch einen Bruch darstellen, in dessen Zähler die Zahl für den Normalamlboceptorgehat, in dessen Nenner die Zahl für die Stärke der bestimmten Reaktion enthalten ist. Beim normalen Liquor, der Lues cerebri und der akuten Meningitis wird nun diese Zahl meist kleiner als 1 sein, -1 ist hier das Maximum; bei der Paralyse sind Zahlen, die kleiner als 1 sind, sehr selten, 
meist ist $1 \frac{1}{3}, 2,2^{2} / 3$, u. a. wenigstens als eine der beiden Zahlen vorhanden. Das heißt, verglichen mit dem durch Phase I nachweisbaren Globulingehalt oder dem Gesamteiweißgehalt ist der Normalamboceptorgehalt der Spinalflüssigkeit der Paralytiker der relativ größte und die besprochene Zahl, die wir den „A ntikör perindex" für die Globuline oder den Gesamteiweißgehalt der Spinalflüssigkeit nennen wollen, zeigt an, um wieviel dieser Gehalt im Vergleiche zum Globulingehalt, dargestellt durch Phase I oder Gesamteiweißgehalt, vermehrt ist. Diese Zahlen sind natürlich diagnostisch weniger brauchbar, sondern nur theoretisch, um uns anzuzeigen, daß es sich bei der Paralyse um einen besonders charakteristischen Ubertritt dieser Antikörper handelt.

Wir konnten also an einem großen Material erweisen, daß zwei Dinge für die Paralyse besonders charakterstisch sind: 1 . Immunkörperübertritt ohne besondere Erhöhung des Gesamteiweißgehaltes, 2. Ubertritt von Eiweißstoffen, die schon, bei 30-33 proz. Ammoniumsulfatsättigung gefällt werden, auch hier ohne besondere Vermehrung der Gesamtglobulin oder des Gesamteiweißgehaltes, ohne aber daß 1. und 2. in enger Beziehung zueinander stehen. Wir müssen, was noch nicht erwähnt, aber wichtig ist, noch hinzufügen, daß sich auch keinerlei engere Beziehungen zwischen 1. und 2. und der Zellmenge der Spinalflüssigkeit bei den Paralysen nachweisen ließen: wenn sich auch in den Fällen mit stärkster Zellvermehrung Amboceptorübergang und Euglobulinreaktion meist nachweisen ließen, so fanden sich auch eine Reihe zellnegativer Spinalflüssigkeiten mit den gleich starken Reaktionen und die Fälle mit verschiedenem Zellgehalt und Minimum zeigten wahllos bald schwächeren bald stärkeren Immunkörper- und Euglobinübertritt. Während wir bei der akuten Meningitis nur auf der Höhe der Entzündung zugleich mit stärkster Zellvermehrung, Polynucleose, größter Eiweißvermehrung Ambozeptorübertritt sehen, während ein gleiches wohl auch für die luischen Meningitiden gilt, sehen wir bei der Paralyse unabhängig von Zellmenge und Gesamteiweißgehalt, unabhängig auch von der Vermehrung der Gesamtglobuline und in den positiven Fällen ständig Immunkörper im Liquor auftreten und in geringerer Anzahl gewisse Eiweißkörper: ein Zeichen für eine ganz bestimmte charakteristische Form der Gefäßveränderung. Es ist daher ganz unverständlich, wenn Zaloziecki ${ }^{18}$ ) auf Grund seines Materials der Hämolysinreaktion jede Bedeutung abspricht. Selbst wenn wir annehmen, daß Zalozieckis Technik der unserigen gleichwertige Befunde ergibt, so muß hier doch auf die Eigenart seines Materials hingewiesen werden. Sehen wir von den akuten nicht luischen Meningitiden ab, so finden wir: Tabes dorsalis 3 Fälle, einer nicht gemacht $=2$ Fälle, einer ,nur kurze klinische Beobachtung“: positiv, einer „,bei dem die 
progressive Paralyse wohl mit Sicherheit auszuschließen war": fraglich. Es sei hier gleich erwähnt, daß wir uns bezüglich der unkomplizierten Tabes aus Mangel an eigenem Material noch reserviert verhalten wollen; auf die Möglichkeit einer Komplikation mit Paralyse oder latenten Inklinationen zur Paralyse ist schon oft genug hingewiesen worden.

Nun weiter zu Zaloziecki: Lues cerebri. Es werden drei Fälle angeführt, von denen $Z$ aloziecki selbst sagt, daß ,mitkonkurrierende Paralyse nicht mit Sicherheit auszuschließen" war; sie seien daher hier nicht herangezogen. Ferner: 5 frühluische Meningitiden, sämtlich Salvarsanneurorezidive mit hochgradigen Liquorveränderu nge n, sehr hohen Zellzahlen, erhöhtem Eiweißgehalt, vier reagierten positiv, einer negativ. Nach dem oben Gesagten ist dies absolut nicht verwunderlich: sehr charakteristisch und für unsere Anschauungen sprechend ist die Tatsache, daß bei dem einen angeführten Fall nach Schmierkur die Hämolysinreaktion mit bedeutendem Herabgehen der anderen Befunde negativ wurde. Hier ist ein Salvarsantodesfall mit ebenfalls sehr hohen Liquorbefunden anzureihen, der positiv reagierte. Sämtliche sechs Fälle sind also Salvarsanmeningitiden! Ein anderer Fall von Lues cerebri reagierte negativ. Daß bei Gehirnabszeß und aseptischer Meningitis die Reaktion positiv ist, wird jeder, der sich mit der Grundlage der Hämolysinreaktion befaßt hat, verständlich finden; das gleiche gilt für die Fälle mit Blutbeimengung zum Liquor über die schon gesprochen ist. Die Tumorxanthochromie, von der Zaloziecki mehrere Fälle bringt, würde ebenfalls nichts Verwunderliches sein: denn entweder sind ständige kleine Blutungen vorhanden, oder durch die Stauung werden Gefäßläsionen erzeugt. Sämtliche Fälle Zalozieckis beweisen nur die Richtigkeit unserer Annahmen und berechtigten keineswegs zu der Folgerung, die Zaloziecki zieht, „daß der Nachweis von Hammelblutamboceptoren im Liquor cerebrospinalis eng an die Vermehrung des Eiweißes desselben gebunden ist und da $B$ es prinzipiell bei allen Krankheiten gelingen muß, die mit Liquoreiweißvermehrung einhergehen". Wir haben die tatsächlichen Verhältnisse aufgedeckt und gezeigt, daß Hammelblutamboceptoren nur in akut meningitischen Krankheitsformen in der Spinalflüssigkeit vorkommen, dann verbunden mit sehr starken anderen Liquorreaktionen, besonders auch Zellreaktionen und meist Komplementübergang, nach Abklingen dieser meningitischen Zustände aber verschwinden, während die Hämolysinreaktion bei der Paralyse ein ständiges und unabhängiges Symptom darstellt. Es muß also bei der Paralyse eine ständige und gleich mäßigePer meabilität der Meningealgefäße vorhanden sein, die durch chronische Meningitis nicht ganz zu erklären ist und vielleicht noch eine Folge der durch die Lues hervorgerufenen „funktionellen" Gefäßerkrankung ist. Ob zum Zustandekommen einer solchen Gefäßerkran- 
kung in frühen Stadien der Lues noch eine Ursache hinzukommen muß oder ob diese in exogenen oder endogenen Faktoren zu suchen ist, müssen Tierexperimente lehren und es ist zu hoffen, daß We ygandts und Jakobs Versuche auch in diese Frage Klärung bringen werden. Fälle von Boas und Neve sprachen jedenfalls dafür. Es müssen ferner auch die anderen Organe und Körperflüssigkeiten nach dieser Richtung hin untersucht werden, da ja diese Gefäßveränderungen nicht auf die Gefäße der Meningen beschränkt bleiben. Einer von uns (Kafka) glaubt in noch nicht abgeschlossenen Versuchen bei Paralytikern ein erhöhtes Abscheiden von Immunkörpern durch den Harn nachweisen zu können.

Nun, das ist alles noch sehr problematisch. Festgestellt aber muß werden, daß sich die oben besprochenen Symptome mit zu jenen anderen stellen, welche der Paralyse die Eigenart verleihen und mit diesen zusammen gedeutet werden müssen, daß also dem Befunde gerade in der jetzigen Zeit, wo durch die Auffindung der Spirochäte die Paralyseforschung einen solchen Schritt nach vorwärts getan hat, theoretischerseits eine große Aufmerksamkeit geschenkt werden müsse. Leider ist dies bis jetzt nicht der Fall gewesen und auch Nonne hat in seinen letzten großen Referaten diese bedeutungsvollen Vorgänge wenig hervorgehoben. Auch die praktische Brauchbarkeit der Hämolysinmethode ist, trotzdem sie nur von wenigen Seiten nachgeprüft wurde, eine hohe. Wir sind Zaloziecki zu großem Danke verpflichtet, daß er durch seine Arbeit uns Anregung zum weiteren Ausbau der Reaktion gegeben hat. Wir müssen aber an dieser Stelle nochmals betonen, daß die Hämolysinreaktion nur nach unserer Technik ausgeführt werden möchte, daß man nur klaren und farblosen Liquor dazu verwende und in der Menge unter $5 \mathrm{ccm}$ nicht herabgehe. Gegenüber der Lues cerebri wird sich die Reaktion mit Erfolg verwerten lassen, weil sie

1. wenn überhaupt, bei der Lues cerebri sehr selten vorkommt und zwar nur bei der meningitischen Form und solange diese dauert,

2. hier immer mit hochgradigen anderen Liquorveränderungen, meist auch mit Polynucleose, Komplementgehalt, Gerinnselbildung einhergeht.

Bei der Paralyse aber ist, wie schon erwähnt, die Hämolysinreaktion ein ständiges Symptom und unabhängig von den anderen Liquorveränderungen.

Freilich ist nicht zu verhehlen, daß hier die Anatomie das letzte Wort sprechen muß, zumal es außer Zweifel ist, daß wir in einer großen Anzahl von Fällen ganz atypische Paralysenbilder sehen und auch dashistologische Bild häufig nicht mehr dem von Nissl und Alzheimer begründeten Typus entspricht. Auch kommt, wie schon erwähnt hinzu, daß heute der subjektive Moment bei der Differentialdiagnose der Paralyse und Lues cerebri eine Rolle spielt und Mißverständnisse häufig vorkommen. 
So haben Weil und Kafka unter „Übergangsfällen“ solche Fälle verstanden, die in die poliklinische Sprechstunde kommen mit refl. Pupillenstarre, Sprach- oder Schreibstörung, Differenz der Reflexe, Fehlen der Achillessehnenreflexe oder ähnliches zeigen, meist längere Jahre nach der Infektion, ohne daß die Psyche auffallend gestört wäre. Diese Fälle stellen uns also initiale Paralyse- und Tabesfälle vor und wir haben dann meist schon genügend Symptome, um die eine oder andere Diagnose mit der größten Wahrseheinlichkeit zu stellen. Wir haben diese Fälle lediglich, um eine charakteristische Gruppe zusammenzufassen, ,Ưbergangsfälle" genannt, zumal sie sich eben auf dem Übergange zur vollen Metalues befinden. Zu solchen Fällen dürften auch drei von den von Mertens ${ }^{10}$ ) positiv nach der Hämolysinreaktion reagierenden Lues cerebri-Fällen zu rechnen sein (Fall Nr. 48, $49,50)$.

Dies genügt wohl, um zu zeigen, wieviel Schwierigkeiten einer richtigen Bewertung der Hämolysinreaktion in theoretischer und praktischer Beziehung entgegenstehen und es bedarf noch der Arbeit vieler, um alle diese Befunde so zu klären, daß wir theoretisch und praktisch bei der noch immer großen Schwierigkeit des Metaluesproblems weiterkommen. Am wenigsten wird aber diesem Zwecke gedient, wenn man von einseitigen Fragestellungen ausgeht und die Ergebnisse zu verallgemeinern versucht oder sie ganz vernachlässigt!

Wenn wir nun auf die Fragestellungen zurückgreifen, von denen wir in der Einleitung ausgegangen sind, so kommen wir $\mathrm{zu}$ folgender

\section{Zusammenfassung.}

1. Bei der progressiven Paralyse finden wir bei genügend hohem Serumtiter in der Spinalflüssigkeit hämolytische Normalamboceptoren für Hammelblut in der Übergangsstärke von $1 / 200-1 / 12$, unabhängig von Globulin- und Gesamteiweißreaktionen, sowie von der Zellmenge der Spinalflüssigkeit, und ständig.

2. Bei der Lues cerebri finden sich hämolytische Normalamboceptoren nur in Fällen, bei denen durch starke Gesamteiweiß- und Globulinreaktionen, durch hohe Zellzahlen (oft polynucleäre Leukocyten), sowie meist durch Komplementgehalt und Gerinnselbildung akut meningitische Erscheinungen angezeigt werden und nur dann, denn sie schwinden weiterhin mit dem Vorbeigehen der meningitischen Symptome, oder nach Behandlung (Boas und Neve). Ein gleiches gilt für die akute Meningitis.

Freilich besteht auch hier kein enger Parallelismus zwischen Eiweiß und Hämolysinreaktion.

3. Diese Verhältnisse lassen sich leicht durch eine Zahl darstellen, die im Zähler eine für den Antikörpergehalt angenommene Zahl, im 
Nenner eine solche für die Stärke der Phase 1 oder den Gesamteiweißgehalt enthält und anzeigt, um wieviel der Antikörpergehalt größer ist als der relative Globulin- oder Gesamteiweilgehalt. Diese Zahl ist bei Paralysen meist größer als 1 , bei allen anderen Krankheiten 1 oder kleiner als 1 (Antikörperindex).

4. Bei steigender Ammoniumsulfatsättigung tritt in der Spinalflüssigkeit der Paralytiker schon bei $33 \%$ in den meisten Fällen beginnende Fällung auf, unabhängig von dem durch die Phase 1 ausgedrückten Gesamtglobulingehalt oder Gesamteiweißgehalt und ist für die Paralyse charakteristisch. Diese Fraktion hat gewisse Beziehungen zum Amboceptorgehalt, ohne aber ihn zu bedingen. Bei 40 proz. Sättigung kann man auch in den anderen Fällen positive Reaktion bekommen, doch ist sie im Paralytikerliquor besonders stark.

Da bei akuter Meningitis die Fällung meist schon bei 28 proz. Sättigung beginnt, kann man bezüglich des Verhaltens der durch verschiedene Ammoniumsulfatsättigung gefällten Globuline differente Kurven für Paralyse, Lues cerebri, akute Meningitis herstellen.

5. Die Eiweißuntersuchung ist der feinste Indikator für krankhafte Veränderung der Spinalflüssigkeit; von Globulinreaktionen geben die schärfsten Ausschläge die Phase 1 und die Pandyreaktion, die besonders bei der Kontrolle der Wirkung von Heilmitteln möglichst beide anzuwenden sind. Zur Gesamteiweißbestimmung kann man die Nisslsche Methode verwenden, wenn man mit den hier geschilderten Kautelen vorgeht. Die Braun-Huslersche Methode zeigt besondere Eiweißstoffe an und ist mit Vorteil für die Paralysediagnose zu verwerten; ob sie mit der Moritz - Reaktion vergleichbar is i, müssen weitere Untersuchungen lehren.

6. Unsere Untersuchungen zeigen wieder, wie notwendig es ist, zur Diagnose und zur theoretischen Klarstellung nicht einzelne Reaktionen, sondern das Gesamtbild verschiedener Untersuchungsmethoden zu verwenden. Wir würden folgenden Weg vorschlagen: nach der gleich nach der Lumbalpunktion vorgenommenen Zellzählung werden die folgenden Proben angesetzt:

I. $1 \mathrm{ccm}$ Liquor $+0,44$ aqua. dest. $+0,56$ Ammoniumsulfat

II. $1 \mathrm{ccm}$ Liquor $+0,34$ aqua. dest. $+0,66$ Ammoniumsulfat

III. $1 \mathrm{ccm}$ Liquor $+1 \mathrm{ccm}$ Ammoniumsulfat $d . h$. die Phase I mit $1 \mathrm{ccm}$, die uns anzeigt, ob irgendwelche besonders syphilogene Veränderungen des Liquors nach der Richtung der Globulinvermehrung vorhanden sind; II richtet bei positivem Ausfall die Diagnose nach der Paralyse hin; während I uns über akut meningitische Veränderung Auskunft gibt.

Ist II also positiv, I negativ, so spricht dies sehr für Paralyse, I und II positiv für akute (auch luische) Meningitis. Sollte II in einem 
paralyseverdächtigen Fall negativ sein, so kann die Ausführung der 40 proz. Ammoniumsulfatprobe, wenn sie ein deutlich positives Resultat gibt, die Paralysendiagnose wahrscheinlich machen. Alle diese Reaktionen können also den Wert der Nonne-Apeltschen Reaktion noch erhöhen, da sie zu ihrer weiteren Spezifizierung beitragen. Im Falle, daß Phase I negativ sein sollte und es sich um einen verdächtigen Fall handelt oder um einen solchen, der nach Behandlung wieder punktiert wird, ist es von Vorteil noch die Pandy-Reaktion anzuschließen, ev, auch die Goldsolreaktion zu machen.

Die Hämolysinreaktion, mit mindestens $5 \mathrm{ccm}$ Liquor vorgenommen, wird uns dann weiter in der Richtung Paralyse führen, da sie auch bej negativer 33 proz. Ammoniumsulfatsättigung und bei schwach positiver Phase I positiv sein kann; im übrigen kommen hier zur Differentialdiagnose gegen Lues cerebri die früher crwähnten Punkte in Betracht. Bei Paralysen werden sich wohl niemals in Begleitung der positiven Hämolysinreaktion so hohe Zell- und Eiweißwerte finden wie bei der Lues cerebri ; über diese Punkte gibt ja auch die 28 proz. Ammoniumsulfatsättigung Auskunft, wenn sie positiv ist.

Die Wassermannsche Reaktion in Blut und Liquor wird uns dann weiter über die luische Natur der konstatierten Liquorveränderungen aufklären. $\mathrm{Zu}$ all diesen Untersuchungen bedarf man maximal $0,25+$ $3+10=13,25 \mathrm{ccm}$, minimal $0,25+3+5=8,25 \mathrm{ccm}$ Liquor, da man den von den roten Hammelblutkörperchen klar abzentrifugierten Liquor ohne Schaden zur Wassermannschen Reaktion verwenden kann.

Die Bestimmung des Gesamteiweißes ist minder wichtig; bei genügender Liquormenge empfiehlt sich auch die Ausführung der Braun-Husler - Methode, die eine Paralysendiagnose bei positivem Ausfall erhärtet. Natürlich $\mathrm{mu} \beta$ im Blute Normalamboceptor und Komplement wenigstens in den Mengen von 0,25 und 0,1 des inaktiven und aktiven Serums bei Verwendung von 0,5 cem einer 5 proz. Hammelblutaufschwemmung bestimmt werden.

Auf diese Weise bekommt man ein Gesamtbild über die Liquorund Blutveränderungen; die Vorzüge solcher Arbeitsweise zeigen sich nicht nur auf diagnostischem Gebiete, sondern auch beim Vergleich der Veränderung bei verschiedenen Punktionen, insbesondere bei der Kontrolle der Behandlung; sie sind aber auch genügend um unsere theoretischen Fragestellungen zu bereichern. Natürlich bleibt nicht unbenommen, bei genügender Liquormenge auch noch andere Methoden hinzuzufügen; die obigen Reaktionen sind ja als Minimum aufgefaßt.

Zur diagnostisch nicht so wichtigen Komplementbestimmung im Liquor genügen die darauf gerichteten Beobachtungen der während der Sensibilisierung auftretenden Vorgänge: Hämolyse, Gelbfärbung 
nach Zentrifugieren. Von zu feinen Methoden ist abzuraten wegen der in der Eigenart der Spinalflüssigkeit liegenden Fehlerquellen.

7. Die Ausbeute unserer Untersuchungen zur Förderung der weiteren Kenntnis der verschiedenen im pathologischen Liquor enthaltenen Eiweißstoffe ist noch nicht genügend groß. Weitere und in die Tiefe gehende Versuche werden hier ausgeführt werden müssen. Immerhin glauben wir festgestellt zu haben, wie sich die im Liquor enthaltenen Eiweißstoffe gegenüber verschiedener Ammoniumsulfatsättigung verhalten, wie also die verschiedenen Globulinfraktionen vertreten sind und glauben in dieser Art die Untersuchungen von W. Reye u. a. fortgeführt zu haben. Auch die festgestellten Beziehungen des Antikörpergehaltes zur Euglobulinfraktion sind auch für weitere Gebiete von Interesse.

8. Wir glauben nachgewiesen zu haben, daß bei der Paralyse eine ständige besonders charakteristische Erhöhung der Gefäßdurchgängigkeit vorhanden ist, die sich vielleicht nicht vollkommen mit chronischer Meningitis erklären läßt, sondern mit einem exogenen oder endogenen Faktor, der vielleicht schon in einem frühen Stadium (oder vor?). der Lues vorhanden, bestimmte Luiker eben zu Paralytikern macht, indem ein ständiges Utbertreten von Spirochäten und vielleicht anderen Stoffen aus der Blutbahn zu den Organen allmählich den Boden vorbereitet zu der Allgemein- und diffusen Hirnerkrankung, wie sie die Paralyse darstellt. Eine solche Theorie würde zwischen den vor der Noguchischen Entdeckung bestehenden und den nach diesem Zeitpunkt entstandenen Anschauungen über die Entstehung der Paralyse eine gewisse Einigung herstellen. Jedenfalls ist zu erkennen, daß unseren Ergebnissen eine Bedeutung für die Klärung der Pathogenese der Paralyse nicht abzusprechen ist.

\section{Literaturverzeichnis.}

1. Boas und Neve, Zeitschr. f. d. ges. Neur. u. Psych. 15, 528. 1913.

2. Fuld und Spiro, Zeitschr. f. physiol. Chemie 31, 32. 1900.

3. Gennerich, Die Liquorveränderungen in den einzelnen Stadien der Syphilis. Berlin.

4. Hofmann, Archiv f. experim. Pathol. u. Pharmakol. 16, 133.

5. Kafka, V., Zeitschr. f. d. ges. Neur. u. Psych. 13, 192 und 15, 482. 1912 und 1913.

6. - Monatsschr. f. Psych. u. Neurol. 27, 414. 1910.

7. - Med. Klin. Nr. 10. 1913.

8. - Deutsche med. Wochenschr. Nr. 39. 1913.

9. Marcus, Zeitschr. f. physiol. Chemie 28, 559. 1899.

10. Mertens, Deutsche Zeitschr. f. Nervenheilk. 49, 170. 1913.

11. Mestrezat, Le Ciquide cephalo-rachidien normal et pathologique. Maloine. Paris 1912. 
12. Plaut, Rehm und Schottmüller, Leitfaden zur Untersuchung der Cerebrospinalflüssigkeit. Jena 1913.

13. Reye, W., Inaug.-Diss. Straßburg. 1898.

14. Spiro, Hofmeisters Beiträge 1, 78. 1901.

15. Weil und Kafka, Wiener klin. Wochenschr. 26, 10. 1911.

16. -- - Med. Klin. 1911, Nr. 34.

17. Zaloziecki, Monatsschr. f. Psych. u. Neur. 26. 1909.

18. - Deutsche Zeitschr. f. Nervenheilk. 46. 195.1913. 